\title{
ATTENUATION OF MODIFIED MERCALLI INTENSITY IN NEW ZEALAND EARTHQUAKES
}

\author{
D.J. Dowrick ${ }^{1,2}$ and D.A. Rhoades ${ }^{1,3}$
}

\begin{abstract}
SUMMARY
The main result of this study is the development of attenuation expressions for Modified Mercalli intensity isoseismals in New Zealand earthquakes, in terms of magnitude $M_{W}$ and source distance. Attenuation of isoseismal intensities has been modelled in a new 2-dimensional manner, i.e. in terms of three distance measures, i.e. radius $a$ along the strike of the fault rupture, radius $b$ normal to strike, and the mean radius $c$. Other factors which are included in the modelling are depth, focal mechanism, tectonic type (i.e. crustal, interface or dipping slab), and regional variations. As well as being implied in the source distance, the moderate effect of depth (to increase intensities) is modelled well with a separate linear depth term. Shallow $\left(h_{C} \leq 60 \mathrm{~km}\right)$ Reverse mechanism events were found to give stronger intensities than Strike-Slip events which in turn were stronger than Normal mechanism events, the difference near source between Reverse and Normal events of $M_{W} 7+$ events being about 0.4 intensity units. Attenuation for the Central Volcanic Region and Deep events differs markedly from the Main Seismic Region. No magnitude saturation effects were found. Comparisons are made with some earlier New Zealand intensity models, and local and international peak ground acceleration attenuation models.
\end{abstract}

\subsection{INTRODUCTION}

The continued high usefulness of the Modified Mercalli $(\mathrm{MM})$ intensity scale in earthquake hazard and risk assessment has prompted the authors to attempt to improve the modelling of attenuation of intensity in earthquakes in New Zealand. Earlier models have been developed by Walley [1], Smith [2-4], Matuschka [5] and Dowrick [6, 7], but all have their weak points, mostly arising from the inadequate quality and quantity of the source and intensity data on which they were based. In the case of the previous models of Dowrick $[6,7]$, concerns were raised $[3,8]$ that the model appeared to underestimate the area of intensity MM10 near the source of the two largest earthquakes in his dataset. This will be shown in this paper to be due to the poor MM10 data then available and to natural interevent variability, rather than to the model. The data available for the present study is superior to that available previously, on the following counts:

- Nine isoseismal maps are available for earthquakes which have occurred since the 1987 cut-off for Dowrick's earlier study $[6,7]$;

- Recent maps have been used of six large early earthquakes: 1855 [9], 1888 [10], 1914 [11, 12], June 1929 [13], 1931 [14] and 5 March 1934 [15];

- In addition the first author has developed (a) MM intensity maps of 12 events [16] dating

\footnotetext{
${ }^{1}$ Institute of Geological \& Nuclear Sciences, Lower Hutt

${ }^{2}$ Fellow

${ }^{3}$ Member
}

from 1922 to 1942 replacing the poor Rossi-Forel intensity conversion maps previously available, e.g. Figure 1(b); (b) 12 completely new maps for events dating from 1901 to 1985 [17], e.g. Figure 1(a); and (c) complete revisions of MM intensity maps for 15 events dating from 1948 - 1990 [18].

- Moment magnitudes are now available for a lot more earthquakes [19-25, 34]. By excluding the use of $M_{L}$, the very large scatter in the relationship between $M_{L}$ and $M_{W}$ [34] involved in all earlier studies [1-7], was eliminated $\left(M_{L}\right.$ differed unsystematically from $M_{W}$ by up to 0.8 magnitude units).

- Better estimates of source depths, focal mechanisms and tectonic types can now be made as a result of various recent special studies [19-33].

In the earlier work by Dowrick [6,7] (which was restricted to earthquakes with depths $\leq 65 \mathrm{~km}$ ), a difference was found between the attenuation of intensity in events of different focal mechanism, but no difference was found with source depth, except that arising from source-to-site distance. A recent study [35] of attenuation of peak ground acceleration (PGA) in New Zealand earthquakes, found that attenuation of PGA depends not only on focal mechanism (for crustal earthquakes) but also on depth and on tectonic type (i.e on whether the source was in the interface between the crust and the dipping slab or not). These factors are all considered below. 


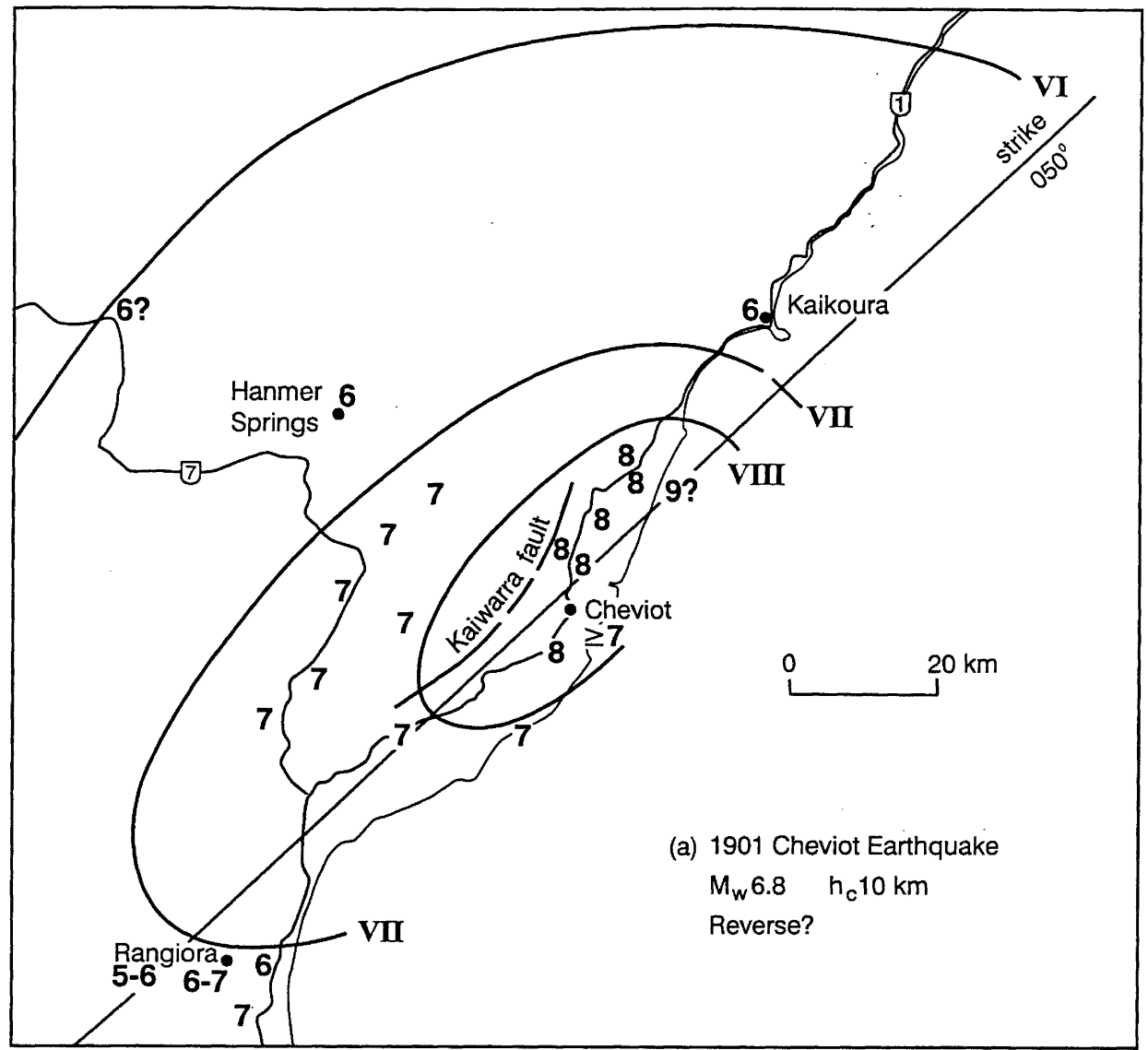

Figure 1(a): Dowrick's inner intensities and isoseismals of the $M_{w} 6.8$ Cheviot earthquake of 1901, and relationship to the local fault system.

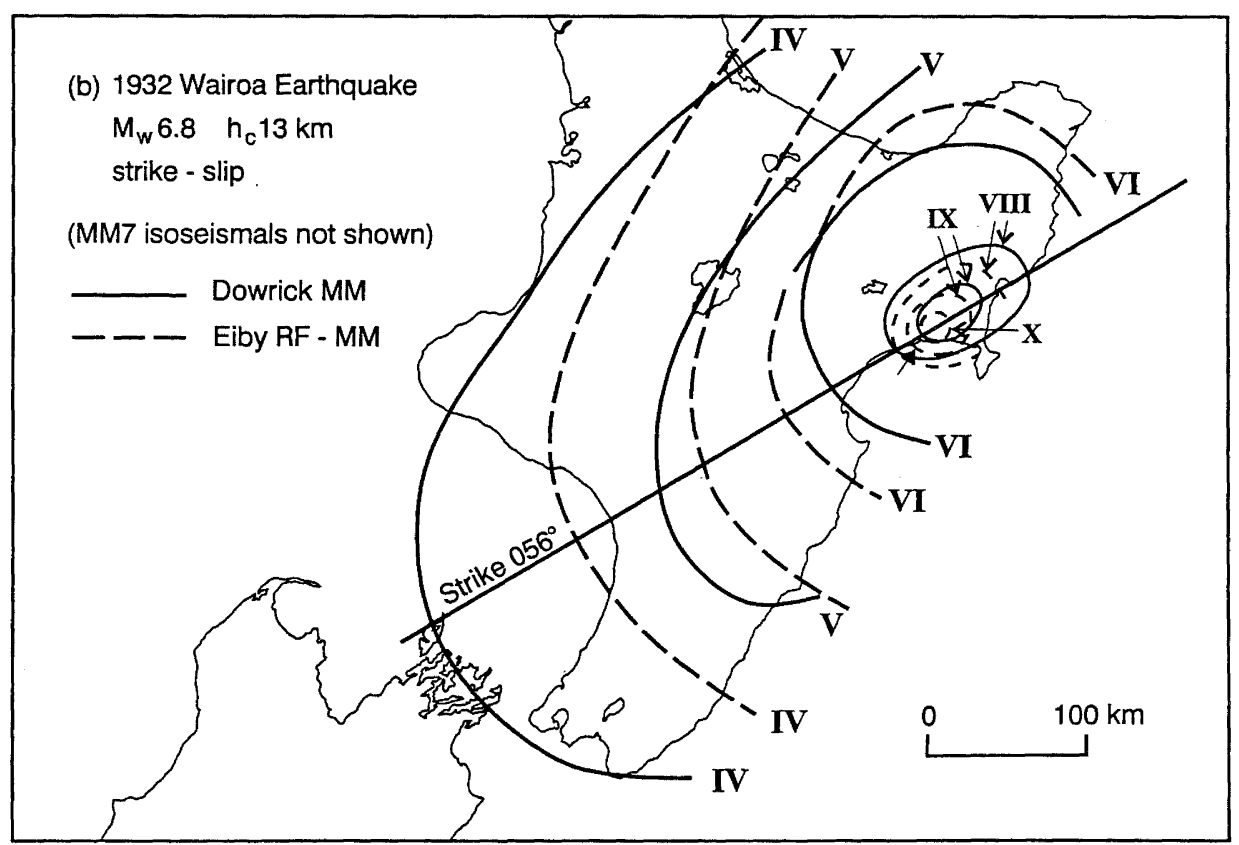

Figure 1(b): Eiby's Rossi-Forel conversion and Dowrick's new MM intensity isoseismals, and relationship to the rupture strike, for the $M_{w} 6.8$ Wairoa earthquake of 1932. 


\section{EARTHQUAKES STUDIED}

The earthquakes used in this study were limited in two ways, i.e.

$\bullet$

Only events for which intensities have been assigned directly in the MM scale were used (i.e. events studied since 1945).

- Only events for which reasonable estimates of moment magnitude $M_{W}$ were available, as qualified below, were used.

In all, 85 earthquakes from the period 1855 - 1998 inclusive were taken into account, as listed in Table 1 . These events range in magnitude from $M_{W} 4.9$ to 8.2 , with 11 being $M_{W} \geq$ 7.0. The moment magnitudes used have been assigned a class $\mathrm{A}, \mathrm{B}, \mathrm{C}$ or $\mathrm{D}$ in descending quality of $M_{W}$ determination. The 28 class A events had their $M_{W}$ calculated seismologically [21-25]. Fifty of the events in Table 1 are $M_{W}$ Class B, which had their moment magnitudes estimated from $M_{S}$ and centroid depth $h_{C}$ by Dowrick and Rhoades [34], who called such magnitudes $\hat{M}_{W}$. For the era pre-1964, $\hat{M}_{W}$ values were adopted here in preference to $M_{W}$ determined by body wave inversions $[26,27]$ because of the high scatter in the latter estimates, the worst example being the body wave inversion $M_{W}$ for the 1929 Murchison earthquake is $M_{W} 7.0$ compared with our [34] $M_{S}=7.8$ and $\hat{M}_{W}=7.7$.

Of the three $M_{W}$ Class C events, $M_{W} 8.2$ for the 1855 earthquake was determined $[19,20]$ from dislocation modelling using changes in ground levels of a somewhat sketchy nature. For the other event pre-dating instrumental magnitudes (1888) Cowan [10] estimated its $M_{S}$ as 7.0-7.3 from its fault rupture length, and $M_{W}=7.1$ was adopted, i.e. in the middle of Cowan's $M_{S}$ range. The four earthquakes with $M_{W}$ Class D were small events (Nos. 11, 36, 65, 66) for which $M_{W}$ was assigned approximately, taking into account the number of stations overseas from New Zealand that reported them [34], as neither $M_{S}$ nor instrumental $M_{S}$ were available.

As seen in Figure 2, the earthquakes are mainly distributed along the eastern part of the North Island and the western part of the South Island, which are regions close to the subduction zones along the boundary between the Pacific and Australian tectonic plates. Ten events provide data related to attenuation in the Central Volcanic Region (CVR) (Figure 2 and Table 1). Because of the presence of the subducting plates, large magnitude events occur down to considerable depths under New Zealand (Figure 3), as indicated by the deepest event in our data set which has a depth of $300 \mathrm{~km}$ and a magnitude $\hat{M}_{\text {W }}$ of 7.3. Of the 85 events in our data set, 12 have depths greater than $50 \mathrm{~km}$ (Figure 2), 11 of which occurred in the dipping slab of the subducting Pacific plate while the other event (1988) was in the dipping Australian plate. The remaining 73 shallower events have depths ranging from 3 to $50 \mathrm{~km}$. As in other studies $[6,7,35]$ the primary depth term used is the depth to the centroid of the rupture, $h_{C}$, rather than the focal depth. The centroid depth estimates have been obtained from various sources, i.e focal mechanism studies [19-27], or aftershock studies [29, 30], or in their absence from reliable focal depths, or from considerations of seismogenic depth in the source region [32, 33] and macroseismic information. The macroseismic procedure was undesirable in relation to depth dependency inferences, but was used only for a few smaller events, and only a priori.

In the data set there are 51 Crustal events, 4 Interface events, 19 dipping slab events with $h_{C} \leq 60 \mathrm{~km}$, and 11 deeper Pacific slab events, denoted $\mathrm{C}, \mathrm{I}, \mathrm{S}_{60}$ and $\mathrm{S}_{\mathrm{D}}$ in Table 1 . In addition to these real earthquakes, two $M_{W} 7.0$ dummy events (Nos. 86 and 87) were introduced to help control the near source modelling of large shallow Normal faulting events in both the CVR and the Main Seismic Region. Without these two events the largest magnitude Normal events were of $M_{W} 6.5$ in both the CVR and the Main Seismic Region Crust.

Information defining source mechanisms is given (Table 1) in two forms, namely rake angle $\gamma$, and the three common geological descriptors, normal (N), strike-slip (S) and reverse (R). Rake is the direction of slip in the fault plane, where the angles $0^{\circ}$ and $180^{\circ}$ represent horizontal movement (pure S), while $90^{\circ}$ and $270^{\circ}$ correspond to pure $\mathrm{R}$ and pure $\mathrm{N}$ respectively. The mechanisms $\mathrm{N}, \mathrm{S}, \mathrm{R}$ given in Table 1 are the predominant mechanisms, which are defined such that $\gamma=$ $315^{\circ}-045^{\circ}$ and $135^{\circ}-225^{\circ}$ is strike-slip; $\gamma=46^{\circ}-134^{\circ}$ is reverse; and $\gamma=226^{\circ}-314^{\circ}$ is normal. Of the crustal events there are 11 reverse, 21 strike-slip, 18 normal and one unknown mechanism. Of the shallow $\left(h_{C} \leq 60 \mathrm{~km}\right)$ Slab events, there are two $R$, two $S, 14 \mathrm{~N}$ and one unknown mechanism, while there are two $\mathrm{R}$ and two $\mathrm{S}$ Interface earthquakes.

Source parameter data in Table 1 incorporate what is considered to be the best quality information available, derived preferably from special studies, as referenced in Table 1.

\subsection{INTENSITY AND DISTANCE DATA}

In the previous study by the first author $[6,7]$, the attenuation of intensity was modelled solely in terms of the mean distance (radius) of the isoseismals from the centroid of the earthquake source. Here we have developed and modified that approach to take account of the shape of each isoseismal in relation to the geometry of the fault rupture surface in a new manner. Because of the importance of modelling the intensities in large surface rupturing earthquakes, the geometry of the isoseismals is measured in relation to fault strike. As shown in Figure 4 the dimensions of the isoseismals are defined as:

$$
\begin{aligned}
& a=\text { horizontal radius along the fault strike; } \\
& b=\text { horizontal radius normal to strike; } \\
& c=\text { mean horizontal radius; } \\
& r_{a}, r_{b}, r_{c}=\text { source(-to-isoseismal) distances } \\
& \quad \text { corresponding to } a, b, c \text {, such that for example }
\end{aligned}
$$

$$
r_{a}=\left(a^{2}+h_{t}^{2}\right)^{1 / 2}
$$

where $h_{t}=$ depth to top of fault rupture. 
Table 1:

Source parameters of earthquakes considered in this study

(see explanatory notes at foot of table)

\begin{tabular}{|c|c|c|c|c|c|c|c|c|c|c|c|c|c|c|c|c|}
\hline No & Date & Time & ${ }^{0} \mathrm{~S}$ & ${ }^{\mathbf{0}} \mathbf{E}$ & $\mathbf{h}$ & $\mathbf{h}_{\mathrm{c}}$ & $\mathbf{h}_{\mathrm{t}}$ & $\mathbf{M}_{\mathbf{w}}$ & $\mathbf{M}_{\mathbf{s}}$ & $\mathbf{T}$ & FM & $\mathbf{R n}$ & $\theta$ & $\beta$ & $\gamma$ & Refs \\
\hline 1 & 1855 Jan 23 & 0932 & 41.40 & 175.00 & sha & 19 & 0 & $8.2 \mathrm{C}$ & - & $\mathrm{C}$ & $S$ & $\mathbf{M}$ & 45 & 90 & 180 & $9,19,20$ \\
\hline 2 & 1888 Aug 31 & 1645 & 42.60 & 172.40 & sha & 8 & 0 & $7.1 \mathrm{C}$ & 7.1 & $\mathrm{C}$ & $S$ & M & 80 & 90 & 180 & 10 \\
\hline 3 & 1901 Nov 15 & 2015 & 42.70 & 173.30 & 12 & 10 & 1 & $6.78 \mathrm{~B}$ & 6.87 & $\mathrm{C}$ & $\mathrm{R}$ ? & M & 50 & 70 & $\mathrm{U}$ & 17,34 \\
\hline 4 & 1911 Oct 5 & 0736 & 39.50 & 177.00 & $25 ?$ & 25 & 23 & $5.56 \mathrm{~B}$ & 5.32 & $\mathrm{~S}_{60}$ & $\mathrm{~N}$ & M & 40 & $\mathrm{U}$ & $\mathrm{U}$ & 17,34 \\
\hline 5 & 1912 May 26 & 0635 & 38.00 & 175.00 & $\mathrm{cru}$ & 10 & 7 & $5.65 \mathrm{~B}$ & 5.52 & $\mathrm{C}$ & $\mathrm{N}$ & $\mathrm{N}$ & 0 & 45 & $\mathrm{U}$ & 17,34 \\
\hline 6 & 1914 Nov 22 & 0814 & 37.50 & 176.50 & 300 & 300 & 300 & $7.29 \mathrm{~B}$ & 6.46 & $S_{D}$ & $\mathrm{U}$ & D & 40 & $\mathrm{U}$ & $\mathrm{U}$ & 11,34 \\
\hline 7 & $1922 \mathrm{Jul} 4$ & 0515 & 38.60 & 176.10 & v.sh & 3 & 0 & $4.93 \mathrm{~B}$ & 4.39 & $\mathrm{C}$ & $\mathrm{N}$ & V & 35 & 45 & $\mathrm{U}$ & 17,34 \\
\hline 8 & $1922 \mathrm{Jul} 14$ & 0356 & 38.60 & 176.10 & v.sh & 3 & 0 & $5.12 \mathrm{~B}$ & 4.73 & $\mathrm{C}$ & $\mathrm{N}$ & V & 35 & 45 & $\mathrm{U}$ & 17,34 \\
\hline 9 & 1922 Sep 5 & 0233 & 38.60 & 176.10 & v.sh & 3 & 0 & $5.37 \mathrm{~B}$ & 5.14 & $\mathrm{C}$ & $\mathrm{N}$ & V & 35 & 45 & $U$ & 17,34 \\
\hline 10 & $1922 \operatorname{Dec} 25$ & 0333 & 43.00 & 173.00 & $10 ?$ & 20 & 15 & $6.79 \mathrm{~B}$ & 6.42 & $\mathrm{C}$ & $S$ & M & 72 & 70 & 170 & $16,34,26$ \\
\hline 11 & 1926 Nov 11 & 2251 & 37.70 & 175.50 & sha & 5 & 3 & $5.0 \mathrm{D}$ & - & $\mathrm{C}$ & $\mathrm{N}$ & $\mathrm{N}$ & 340 & 45 & $\mathrm{U}$ & 17,34 \\
\hline 12 & 1929 Mar 9 & 1050 & 42.80 & 171.90 & $15 ?$ & 11 & 0 & $6.95 \mathrm{~B}$ & 7.05 & $\mathrm{C}$ & $S$ & M & 65 & 90 & 178 & $16,34,26$ \\
\hline 13 & 1929 May 7 & 1614 & 40.00 & 175.50 & cru & 10 & 8 & $5.45 \mathrm{~B}$ & 5.22 & $\mathrm{C}$ & $\mathrm{S}$ & M & 32 & $\mathrm{U}$ & $\mathrm{U}$ & 17,34 \\
\hline 14 & 1929 Jun 16 & 2247 & 41.70 & 172.20 & $15 ?$ & 9 & 0 & $7.72 \mathrm{~B}$ & 7.79 & $\mathrm{C}$ & $\mathrm{R}$ & M & 5 & 45 & 69 & 13,34 \\
\hline 15 & 1931 Feb 2 & 2246 & 39.30 & 177.00 & 30 & 17 & 5 & $7.79 \mathrm{~B}$ & 7.83 & $\mathrm{C}$ & $\mathbf{R}$ & M & 40 & 45 & $\mathrm{U}$ & 14,34 \\
\hline 16 & 1932 May 5 & 0823 & 39.60 & 176.90 & $25 ?$ & 20 & 17 & $6.05 \mathrm{~B}$ & 5.87 & $S_{60}$ & $\mathrm{~N}$ & M & 40 & $\mathrm{U}$ & $\mathrm{U}$ & 16,34 \\
\hline 17 & 1932 Sep 15 & 1355 & 38.90 & 177.60 & $30 ?$ & 13 & 3 & $6.79 \mathrm{~B}$ & 6.87 & $\mathrm{C}$ & $S$ & $\mathbf{M}$ & 56 & 82 & 167 & $16,34,27$ \\
\hline 18 & 1934 Mar 5 & 1146 & 40.51 & 176.29 & 12 & $10 ?$ & 0 & $7.3 \mathrm{C}$ & 7.56 & $\mathrm{C}$ & $S$ & M & 40 & 90 & $\mathrm{U}$ & $16,34,27$ \\
\hline 19 & 1934 Mar 15 & 1046 & 39.31 & 177.17 & 10 & 40 & 35 & $6.42 \mathrm{~B}$ & 6.37 & $S_{60}$ & $\mathrm{~N}$ & $\mathbf{M}$ & 35 & $\mathrm{U}$ & $\mathrm{U}$ & 16,34 \\
\hline 20 & $1938 \mathrm{Dec} 15$ & 0912 & 40.00 & 177.00 & $30 ?$ & 25 & 22 & $5.76 \mathrm{~B}$ & 5.61 & $\mathrm{~S}_{60}$ & $\mathrm{~N}$ & M & 36 & $\mathrm{U}$ & $\mathrm{U}$ & 16,34 \\
\hline 21 & $1938 \operatorname{Dec} 16$ & 1721 & 45.00 & 167.00 & 60 & 47 & 40 & $7.06 \mathrm{~B}$ & 7.05 & $S_{60}$ & $\mathrm{R}$ & $\mathrm{F}$ & 117 & 88 & 72 & $16,34,26$ \\
\hline 22 & 1942 Jun 24 & 1116 & 40.90 & 175.90 & 15 & 12 & $4 ?$ & $7.07 \mathrm{~B}$ & 7.16 & $\mathrm{C}$ & $S$ & M & 35 & 86 & 170 & $16,34,27$ \\
\hline 23 & 1942 Aug 1 & 1234 & 41.00 & 175.80 & 43 & 40 & 35 & $6.96 \mathrm{~B}$ & 6.97 & $S_{60}$ & $\mathrm{~N}$ & M & 28 & 67 & 293 & $16,34,27$ \\
\hline 24 & 1943 Feb 17 & 0215 & 45.19 & 167.04 & $33 \mathrm{R}$ & 36 & 32 & $6.37 \mathrm{~B}$ & 6.33 & $S_{60}$ & $S$ & $\mathrm{~F}$ & 50 & 52 & 15 & $17,34,26$ \\
\hline 25 & 1943 Aug 2 & 0046 & 46.27 & 166.72 & $31 \mathrm{R}$ & 31 & 27 & $6.57 \mathrm{~B}$ & 6.58 & $\mathrm{C}$ & $S$ & $\mathrm{~F}$ & 34 & 53 & 6 & $17,34,26$ \\
\hline 26 & 1946 Feb 12 & 0616 & 39.79 & 174.85 & 132 & 132 & 132 & $5.77 \mathrm{~B}$ & 5.14 & $S_{D}$ & $\mathrm{U}$ & $\mathrm{D}$ & 40 & $\mathrm{U}$ & U & 17,34 \\
\hline 27 & 1946 Jun 26 & 1234 & 43.46 & 171.26 & $12 \mathrm{R}$ & 9 & 5 & $6.32 \mathrm{~B}$ & 6.37 & $\mathrm{C}$ & $S$ & M & 44 & 89 & 180 & $12,34,26$ \\
\hline 28 & 1948 May 22 & 1921 & 42.48 & 172.99 & $12 \mathrm{R}$ & 4 & 1 & $6.36 \mathrm{~B}$ & 6.43 & $\mathrm{C}$ & $S$ & M & 60 & 90 & 177 & $18,34,26$ \\
\hline $\begin{array}{l}29 \\
30\end{array}$ & $\begin{array}{l}1951 \text { Jan } 10 \\
1951 \text { Feb } 10\end{array}$ & $\begin{array}{l}1915 \\
0327\end{array}$ & $\begin{array}{l}42.79 \\
40.21\end{array}$ & $\begin{array}{l}173.18 \\
177.04\end{array}$ & $\begin{array}{l}12 R \\
33 R\end{array}$ & $\begin{array}{l}10 \\
20\end{array}$ & $\begin{array}{r}7 \\
15\end{array}$ & $\begin{array}{l}5.93 \mathrm{~B} \\
6.21 \mathrm{~B}\end{array}$ & $\begin{array}{l}5.89 \\
6.20\end{array}$ & $\begin{array}{l}\mathrm{C} \\
\mathrm{S}_{60}\end{array}$ & $\begin{array}{l}\mathrm{R} ? \\
\mathrm{~N}\end{array}$ & $\begin{array}{l}\mathrm{M} \\
\mathrm{M}\end{array}$ & $\begin{array}{l}30 \\
35\end{array}$ & $\begin{array}{l}\mathrm{U} \\
\mathrm{U}\end{array}$ & $\begin{array}{l}\mathrm{U} \\
\mathrm{U}\end{array}$ & $\begin{array}{l}18,34 \\
12,34\end{array}$ \\
\hline 31 & 1951 Apr 23 & 0650 & 37.53 & 177.84 & $80 \mathrm{R}$ & 80 & 76 & $5.99 \mathrm{~B}$ & 5.65 & $S_{D}$ & $\mathrm{U}$ & $\mathrm{D}$ & 40 & $\mathrm{U}$ & $\mathrm{U}$ & 12,34 \\
\hline 32 & 1951 Jun 24 & 0441 & 39.46 & 176.20 & $33 \mathrm{R}$ & 25 & 23 & $5.51 \mathrm{~B}$ & 5.25 & $\mathrm{C}$ & S? & M & 27 & $U$ & $\mathrm{U}$ & 12,34 \\
\hline 33 & 1952 Aug 28 & 1040 & 39.99 & 176.96 & $12 \mathrm{R}$ & 30 & 26 & $6.01 \mathrm{~B}$ & 5.91 & $\mathrm{~S}_{60}$ & $\mathrm{U}$ & $\mathrm{M}$ & 35 & $\mathrm{U}$ & $\mathrm{U}$ & 12,34 \\
\hline 34 & $1953 \mathrm{Jul} 4$ & 0207 & 38.86 & 175.68 & $12 \mathrm{R}$ & 5 & 3 & $5.28 \mathrm{~B}$ & 4.99 & $\mathrm{C}$ & $\mathrm{N}$ & VM & 0 & 45 & $\mathrm{U}$ & 12,34 \\
\hline 35 & 1956 Jan 30 & 0843 & 37.10 & 177.42 & $12 \mathrm{R}$ & 6 & 0 & 6.34B & 6.37 & $\mathrm{C}$ & $\mathrm{N}$ & $\mathrm{V}$ & 35 & 65 & $\mathrm{U}$ & 12,34 \\
\hline 36 & 1956 Mar 2 & 2243 & 38.90 & 175.80 & $12 \mathrm{R}$ & 5 & 3 & $5.0 \mathrm{D}$ & - & $\mathrm{C}$ & $\mathrm{N}$ & $\mathrm{V}$ & $\mathrm{U}$ & 45 & $\mathrm{U}$ & 18,34 \\
\hline 37 & 1957 Feb 22 & 0030 & 39.19 & 175.14 & $5 R$ & 15 & 13 & $5.25 \mathrm{~B}$ & 4.88 & $\mathrm{C}$ & $\mathrm{N}$ & M & 35 & 45 & $\mathrm{U}$ & 18,34 \\
\hline 38 & 1957 Aug 11 & 0512 & 39.05 & 175.97 & 99 & 99 & 96 & $5.52 \mathrm{~B}$ & 4.90 & $S_{D}$ & $\mathrm{U}$ & $\mathrm{D}$ & 40 & $\mathrm{U}$ & $\mathrm{U}$ & 17,34 \\
\hline 39 & 1958 Jan 31 & 0632 & 39.85 & 176.58 & $12 \mathrm{R}$ & 35 & 33 & $5.46 \mathrm{~B}$ & 5.12 & $S_{60}$ & $\mathrm{~N}$ & M & 36 & $\mathrm{U}$ & $\mathrm{U}$ & 18,34 \\
\hline 40 & 1959 May 22 & 0657 & 41.07 & 174.30 & $33 \mathrm{R}$ & 40 & 40 & $5.29 \mathrm{~B}$ & 4.83 & $\mathrm{C}$ & U & M & 40 & 30 & $\mathrm{U}$ & 12,34 \\
\hline 41 & 1960 Feb 3 & 0221 & 37.61 & 178.04 & 144 & 144 & 144 & $5.79 \mathrm{~B}$ & 5.11 & $\mathrm{~S}_{\mathrm{D}}$ & $\mathrm{U}$ & $\mathrm{D}$ & 40 & $\mathrm{U}$ & $\mathrm{U}$ & 18,34 \\
\hline 42 & 1960 May 24 & 1446 & 44.17 & 167.73 & $50 \mathrm{R}$ & 9 & 4 & $6.46 \mathrm{~B}$ & 6.53 & $\mathrm{C}$ & $\mathrm{N}$ & $\mathrm{F}$ & 265 & 67 & 260 & 18,34 \\
\hline 43 & 1962 Jan 23 & 0649 & 38.58 & 174.80 & $12 \mathrm{R}$ & 15 & 13 & $5.01 \mathrm{~B}$ & 4.47 & $\mathrm{C}$ & $\mathrm{N}$ & $\mathrm{N}$ & 0 & 45 & $\mathrm{U}$ & 12,34 \\
\hline 44 & 1962 May 10 & 0027 & 41.67 & 171.44 & $12 \mathrm{R}$ & 8 & 5 & $5.91 \mathrm{~B}$ & 5.88 & $\mathrm{C}$ & $\mathrm{R}$ & M & 55 & 40 & 88 & $12,34,26$ \\
\hline 45 & 1962 Oct 15 & 2336 & 43.54 & 169.77 & $12 \mathrm{R}$ & 20 & 18 & $5.57 \mathrm{~B}$ & 5.36 & $\mathrm{C}$ & $S$ & M & 55 & $\mathrm{U}$ & $\mathrm{U}$ & 12,34 \\
\hline 46 & 1963 Apr 12 & 0841 & 38.71 & 176.76 & $12 \mathrm{R}$ & 20 & 17 & $5.82 \mathrm{~B}$ & 5.71 & $\mathrm{C}$ & $S$ & M & 15 & $\mathrm{U}$ & $\mathrm{U}$ & 12,34 \\
\hline $\begin{array}{l}47 \\
48\end{array}$ & $\begin{array}{l}1963 \operatorname{Dec} 22 \\
1964 \operatorname{Mar} 8\end{array}$ & $\begin{array}{l}1335 \\
0135\end{array}$ & $\begin{array}{l}35.10 \\
44.30\end{array}$ & $\begin{array}{l}173.50 \\
167.87\end{array}$ & $\begin{array}{l}12 \mathrm{R} \\
12 \mathrm{R}\end{array}$ & $\begin{array}{l}6 \\
5\end{array}$ & $\begin{array}{l}4 \\
2\end{array}$ & $\begin{array}{l}4.93 \mathrm{~B} \\
5.89 \mathrm{~A}\end{array}$ & $\begin{array}{l}4.36 \\
5.80\end{array}$ & $\mathrm{C}$ & $\begin{array}{l}N \\
S\end{array}$ & $\mathrm{~N}$ & 64 & 45 & U & 12,34 \\
\hline 49 & 1965 Apr 11 & 0011 & 42.74 & 174.10 & $12 \mathrm{R}$ & 16 & 13 & $6.09 \mathrm{~A}$ & 5.75 & $S_{60}$ & $\mathrm{~N}$ & M & 110 & $\begin{array}{l}83 \\
55\end{array}$ & $\begin{array}{l}141 \\
297\end{array}$ & $\begin{array}{l}12,21 \\
12,21\end{array}$ \\
\hline 50 & 1965 Jun 15 & 0920 & 37.90 & 177.53 & $33 R$ & 50 & 47 & $5.62 \mathrm{~B}$ & 5.30 & $S_{60}$ & $\mathrm{~N}$ & M & 37 & $\mathrm{U}$ & $U$ & 12,22 \\
\hline
\end{tabular}


Table 1 continued:

\begin{tabular}{|c|c|c|c|c|c|c|c|c|c|c|c|c|c|c|c|c|}
\hline No & Date & Time & ${ }^{\circ} \mathrm{S}$ & ${ }^{{ }^{\circ} \mathbf{E}}$ & $\bar{h}$ & $\mathbf{h}_{\mathrm{c}}$ & $\mathbf{h}_{\mathbf{t}}$ & $\mathbf{M}_{\mathbf{w}}$ & $\mathbf{M}_{\mathbf{s}}$ & $\mathbf{T}$ & FM & $\mathbf{R n}$ & $\theta$ & $\beta$ & $\gamma$ & Refs \\
\hline 51 & $1965 \operatorname{Dec} 8$ & 1805 & 37.09 & 177.50 & 156 & 156 & 156 & $6.11 \mathrm{~A}$ & - & $S_{D}$ & $\mathrm{U}$ & $\mathrm{D}$ & 40 & $\mathrm{U}$ & $\mathrm{U}$ & 12,22 \\
\hline 52 & 1966 Mar 4 & 2358 & 38.45 & 177.91 & $33 \mathrm{R}$ & 24 & 21 & $5.64 \mathrm{~A}$ & 5.77 & I & $S$ & $\mathbf{M}$ & 197 & 15 & 8 & 18,22 \\
\hline 53 & 1966 Apr 23 & 0649 & 41.63 & 174.40 & 22 & 19 & 16 & $5.75 \mathrm{~A}$ & 5.62 & $\mathrm{C}$ & $\mathrm{R}$ & $\mathbf{M}$ & 232 & 66 & 133 & 12,21 \\
\hline 54 & 1968 May 23 & 1724 & 41.76 & 171.96 & 15 & 10 & 0 & $7.23 \mathrm{~A}$ & 7.41 & $\mathrm{C}$ & $\mathrm{R}$ & $\mathbf{M}$ & 27 & 45 & 103 & 12,21 \\
\hline 55 & 1968 Sep 25 & 0702 & 46.49 & 166.68 & $12 \mathrm{R}$ & 4 & 0 & $6.27 \mathrm{~A}$ & 6.15 & $\mathrm{C}$ & $S$ & $\mathbf{M}$ & 60 & 85 & 182 & 18,21 \\
\hline 56 & 1968 Nov 1 & 0132 & 41.62 & 175.05 & $33 R$ & 25 & 23 & $5.35 \mathrm{~B}$ & 4.99 & $S_{60}$ & $\mathrm{~N}$ & M & 37 & $\mathrm{U}$ & $\mathrm{U}$ & 12,34 \\
\hline 57 & 1971 Aug 13 & 1442 & 42.13 & 172.10 & $12 \mathrm{R}$ & 9 & 6 & $5.70 \mathrm{~A}$ & 5.55 & $\mathrm{C}$ & $\mathrm{S}$ & $\mathbf{M}$ & 242 & 83 & 207 & 18,21 \\
\hline 58 & $1972 \operatorname{Jan} 8$ & 2133 & 37.57 & 175.69 & $12 \mathrm{R}$ & 7 & 5 & $5.26 \mathrm{~B}$ & 4.94 & $\mathrm{C}$ & $\mathrm{N}$ & $\mathrm{N}$ & 335 & 45 & $\mathrm{U}$ & 12,34 \\
\hline 59 & 1973 Jan 5 & 1354 & 39.04 & 175.25 & 160 & 149 & 149 & $6.57 \mathrm{~A}$ & 6.27 & $S_{D}$ & $\mathrm{R}$ & $\mathrm{D}$ & 40 & $\mathrm{U}$ & $\mathrm{U}$ & 12,22 \\
\hline 60 & 1974 Sep 20 & 1948 & 44.40 & 167.99 & $12 \mathrm{R}$ & 25 & 23 & $5.55 \mathrm{~B}$ & 5.30 & $\mathrm{C}$ & $\mathrm{R}$ & $\mathrm{F}$ & 55 & 45 & $\mathrm{U}$ & 12,34 \\
\hline 61 & 1974 Nov 5 & 1038 & 39.65 & 173.63 & $12 \mathrm{R}$ & 17 & 14 & $5.44 \mathrm{~A}$ & 5.45 & $\mathrm{C}$ & $S$ & M & 195 & 41 & 213 & 18,22 \\
\hline 62 & 1975 Jan 4 & 2037 & 40.77 & 174.67 & 72 & 72 & 70 & $5.24 \mathrm{~B}$ & 4.56 & $S_{D}$ & $\mathrm{U}$ & $\mathrm{D}$ & 40 & $\mathrm{U}$ & $\mathrm{U}$ & 12,34 \\
\hline 63 & 1975 Jun 10 & 1011 & 40.34 & 175.93 & $33 \mathrm{R}$ & 38 & 36 & $5.62 \mathrm{~A}$ & 5.14 & $\mathrm{C}$ & $\mathrm{N}$ & $\mathbf{M}$ & 250 & 56 & 257 & 18,22 \\
\hline 64 & 1976 May 4 & 1356 & 44.67 & 167.45 & $12 \mathrm{R}$ & 10 & 5 & $6.51 \mathrm{~A}$ & 6.38 & $\mathrm{C}$ & $\mathrm{R}$ & $\mathrm{F}$ & 48 & 47 & 130 & 12,21 \\
\hline 65 & 1976 Oct 27 & 2057 & 37.83 & 176.34 & $12 \mathrm{R}$ & 5 & 3 & $5.0 \mathrm{D}$ & - & $\mathrm{C}$ & $\mathrm{N}$ & $\mathrm{V}$ & 20 & 45 & $\mathrm{U}$ & 12,34 \\
\hline 66 & 1976 Dec 5 & 0457 & 38.17 & 175.51 & $1 \mathrm{~A}$ & 5 & 3 & $5.0 \mathrm{D}$ & - & $\mathrm{C}$ & $\mathrm{N}$ & $\mathrm{N}$ & 335 & 45 & $\mathrm{U}$ & 12,34 \\
\hline 67 & $1977 \operatorname{Jan} 18$ & 0541 & 41.73 & 174.30 & $33 R$ & 34 & 30 & $6.02 \mathrm{~A}$ & 5.93 & $S_{60}$ & $\mathrm{~N}$ & $\mathbf{M}$ & 213 & 68 & 251 & 12,22 \\
\hline 68 & 1977 May 31 & 1850 & 37.88 & 176.81 & 9 & 6 & 4 & $5.39 \mathrm{~B}$ & 5.15 & $\mathrm{C}$ & $\mathrm{N}$ & V & 30 & 45 & $U$ & 12,34 \\
\hline 69 & 1979 Oct 12 & 1025 & 46.69 & 165.74 & $12 \mathrm{R}$ & 12 & 5 & $7.23 \mathrm{~A}$ & 7.24 & $\mathrm{C}$ & $\mathbf{R}$ & $\mathbf{M}$ & 7 & 24 & 120 & 12,21 \\
\hline 70 & $1982 \operatorname{Sep} 2$ & 1558 & 39.74 & 176.93 & 46 & 31 & 29 & $5.38 \mathrm{~B}$ & 5.02 & $S_{60}$ & $\mathrm{~N}$ & M & 35 & $\mathrm{U}$ & $\mathrm{U}$ & 18,34 \\
\hline 71 & 1983 Dec 14 & 2056 & 38.36 & 176.33 & $5 \mathrm{R}$ & 3 & 1 & $5.06 \mathrm{~B}$ & 4.62 & $\mathrm{C}$ & $\mathrm{N}$ & V & 30 & 45 & $\mathrm{U}$ & 12,34 \\
\hline 72 & 1984 Mar 8 & 0041 & 38.31 & 177.29 & 75 & 80 & 76 & $5.91 \mathrm{~A}$ & 5.40 & $S_{D}$ & $\mathrm{R}$ & $\mathrm{D}$ & 40 & $\mathrm{U}$ & $\mathrm{U}$ & 18,22 \\
\hline 73 & 1984 Jun 24 & 1329 & 43.60 & 170.56 & $5 R$ & 13 & 9 & $6.12 \mathrm{~A}$ & 6.07 & $\mathrm{C}$ & $S$ & $\mathbf{M}$ & 62 & 83 & 206 & 18,21 \\
\hline 74 & 1985 Jul 19 & 1433 & 38.72 & 177.30 & 41 & 31 & 28 & $5.92 \mathrm{~A}$ & 5.90 & $S_{60}$ & $\mathrm{~N}$ & M & 213 & 73 & 255 & 17,22 \\
\hline 75 & 1987 Mar 2 & 0142 & 37.88 & 176.84 & $10 \mathrm{R}$ & 6 & 0 & $6.53 \mathrm{~A}$ & 6.62 & $\mathrm{C}$ & $\mathrm{N}$ & $\mathrm{V}$ & 49 & 45 & 257 & 12,22 \\
\hline 76 & 1988 Jun 3 & 2327 & 45.10 & 167.17 & 57 & 60 & 54 & $6.69 \mathrm{~A}$ & 6.50 & $S_{60}$ & $\mathrm{R}$ & $\mathrm{F}$ & 281 & $\mathrm{U}$ & 118 & $12,21,31$ \\
\hline 77 & 1989 May 31 & 0554 & 45.27 & 166.88 & $23 \mathrm{R}$ & 24 & 20 & $6.33 \mathrm{~A}$ & 6.26 & I & $S$ & $\mathrm{~F}$ & 26 & 48 & 148 & 12,21 \\
\hline 78 & 1990 Feb 10 & 0327 & 42.25 & 172.65 & 13 & 8 & 2 & $5.93 \mathrm{~A}$ & 6.04 & $\mathrm{C}$ & $S$ & M & 55 & 89 & 163 & $12,21,28$ \\
\hline 79 & 1990 Feb 19 & 0534 & 40.38 & 176.22 & 24 & 27 & 24 & $6.23 \mathrm{~A}$ & 6.45 & $S_{60}$ & $\mathrm{~N}$ & M & 35 & 70 & 316 & $18,22,29$ \\
\hline 80 & 1990 May 13 & 0423 & 40.35 & 176.23 & 12 & 13 & 9 & $6.37 \mathrm{~A}$ & 6.40 & $\mathrm{C}$ & $\mathbf{R}$ & M & 40 & 40 & 111 & $17,22,30$ \\
\hline 81 & 1993 Apr 11 & 0659 & 39.74 & 176.52 & 35 & 24 & 22 & $5.63 \mathrm{~A}$ & 5.54 & I & $\mathbf{R}$ & M & 45 & 15 & $\mathrm{U}$ & 17,23 \\
\hline 82 & 1993 Aug 10 & 0051 & 45.21 & 166.71 & $5 \mathrm{R}$ & 20 & 18 & $6.81 \mathrm{~A}$ & 6.98 & I & $\mathbf{R}$ & $\mathrm{F}$ & 32 & 15 & U & 18,22 \\
\hline 83 & 1993 Aug 10 & 0946 & 38.52 & 177.87 & 36 & 39 & 30 & $6.19 \mathrm{~A}$ & 6.17 & $S_{60}$ & $S$ & M & 354 & U & U & 18,22 \\
\hline 84 & 1995 Mar 22 & 1943 & 41.05 & 174.18 & 90 & 90 & 86 & $5.83 \mathrm{~A}$ & - & $S_{D}$ & $S$ & $\mathrm{D}$ & 40 & $\mathrm{U}$ & $\mathrm{U}$ & 17,25 \\
\hline 85 & $1998 \mathrm{Jul} 09$ & 1445 & 30.75 & 180.86 & $\mathrm{U}$ & 146 & 146 & $6.91 \mathrm{~A}$ & $\mathbf{U}$ & $S_{D}$ & $\mathrm{U}$ & D & $\mathrm{U}$ & $\mathrm{U}$ & $\mathrm{U}$ & 17,25 \\
\hline 86 & Dummy A & & & & & 7 & 0 & $7.0 \mathrm{~A}$ & & $\mathrm{C}$ & $\mathrm{N}$ & $\mathrm{M}$ & & & & \\
\hline 87 & Dummy B & & & & & 7 & 0 & $7.0 \mathrm{~A}$ & & $\mathrm{C}$ & $\mathrm{N}$ & V & & & & \\
\hline
\end{tabular}

Notes:

$\begin{array}{lll}T= & \text { Tectonic Type }\left(\mathrm{C}, \mathrm{S}_{60}, \mathrm{I}\right) & \theta=\text { strike } \\ \mathrm{FM}= & \text { Focal Mechanism }(\mathrm{N}, \mathrm{R}, \mathrm{S}) & \beta=\text { dip } \\ \mathrm{Rn}= & \text { Region }(\mathrm{D}, \mathrm{F}, \mathrm{M}, \mathrm{N}, \mathrm{V}) & \gamma=\text { rake } \\ \mathrm{U}= & \text { Undefined or Unknown } & \end{array}$

It is noted that while the actual isoseismals were of course not pure ellipses many of them were reasonably elliptical and nearly symmetrical about the fault strike (e.g. Figure 1).

The depth to the top of the fault rupture was estimated in a number of ways, depending on the information available, such as surface rupturing (12 events), or from aftershock studies (Events 76, 78-83) [28-33]. For events where such information was not available, $h_{t}$ was estimated from

$$
h_{t}=h_{c}-0.5 h_{f}
$$


where $h_{f}=W \sin \beta$

where $W=$ fault width

and $\beta=$ fault dip. for events of $h_{C}>100 \mathrm{~km}$ it was assumed that $h_{t}=h_{C}$. This model for $W$ was considered to be reasonably representative of widths of different styles of faulting in interplate regions, but is not based on any specific model.

For the purposes of the above calculations $W$ was taken as 4 , $7,11,14 \mathrm{~km}$ for $M_{W} 5.5,6.0,6.5,7.0$ respectively, except that

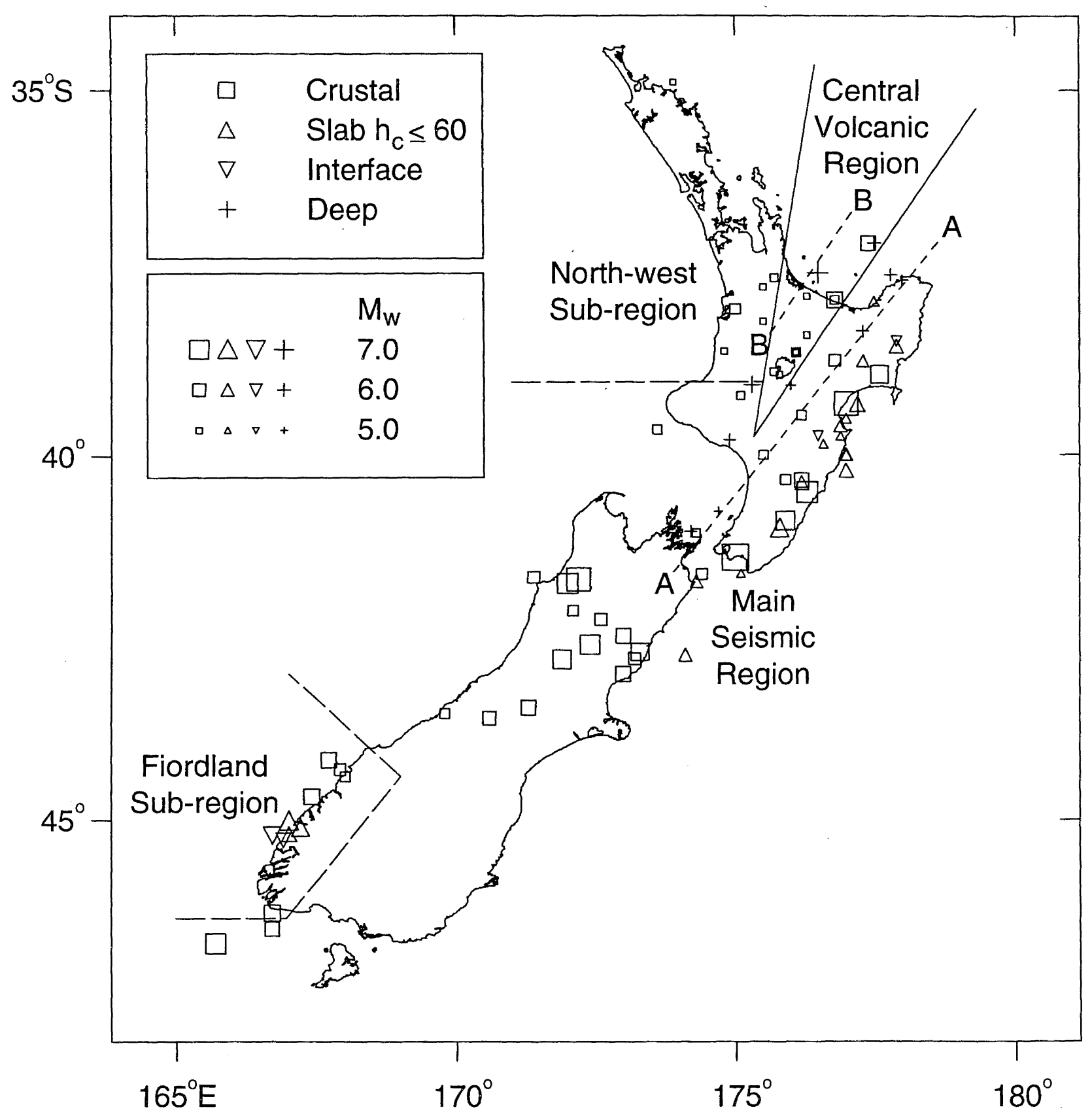

Figure 2: $\quad$ Map of locations of earthquakes considered in this study (Except Event 85, which is at latitude $30.75^{\circ}$ S). The regions considered for differences in attenuation, CVR, Fiordland and North-west are indicated, as are events of Crustal, Slab $\left(h_{C} \leq 60 \mathrm{~km}\right)$, Deep Pacific Slab $\left(h_{C} \geq 70 \mathrm{~km}\right)$ and Interface origins. 
The values adopted for $h_{t}$ and $\beta$ are given in Table 1 . The values for $a, b, c$ and $b / a$ are given in Table 2, weakly constrained values being omitted (except in a few cases where such data were found to be adequate for bolstering small subsets (CVR and Deep) or helping near source control of the models.)

It is noted that for calculating the source distance $r_{b}$ for earthquakes classified as Deep, the approximation is made that the horizontal offset of the source from the Major Axis (Figure 5) is assumed to be zero.

The isoseismal map of the $M_{W} 7.21979$ Puysegur Bank earthquake (Figure 6) illustrates some issues relating to measurement of isoseismal dimensions $a, b$ and $c$. In this case the epicentre is offshore and the strike angle $\theta=7^{\circ}$ is such that the whole of the strike vector lies well offshore. No values of $a$ have been measured because to do so would have involved considerable extrapolation of the isoseismals. Thus the only dimensions deemed well enough constrained for use as data were $b$ and $c$ for MM5 and $c$ for MM4. While the use of this map provides data from a valuable (large magnitude) event, the distance data is less well defined than for a comparable land-based event because $b$ and $c$ are measured from the epicentre (because it is offshore), rather than being half the isoseismal dimension. In general epicentres are not at the centre of their associated isoseismal patterns, although in many cases they are within small distances of it. In addition there is a locational uncertainty in the epicentre, which is likely to be $10 \mathrm{~km}$ or so. However, overall these sources of error amount to only $5-10 \%$ of the values of $a, b$ and $c$.

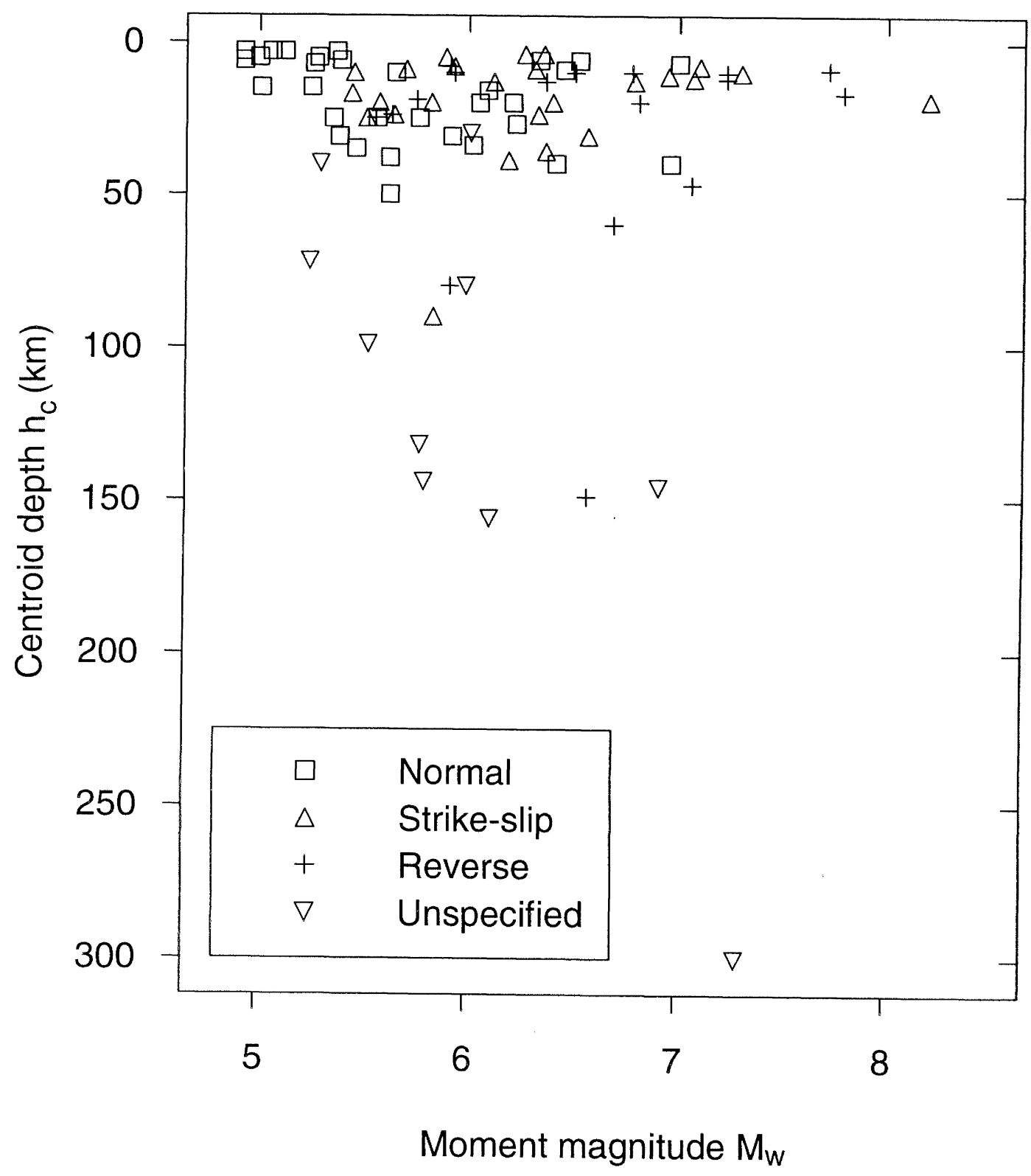

Figure 3: Depth $h_{C}$, focal mechanism and $M_{W}$ for the earthquakes considered in this study. 


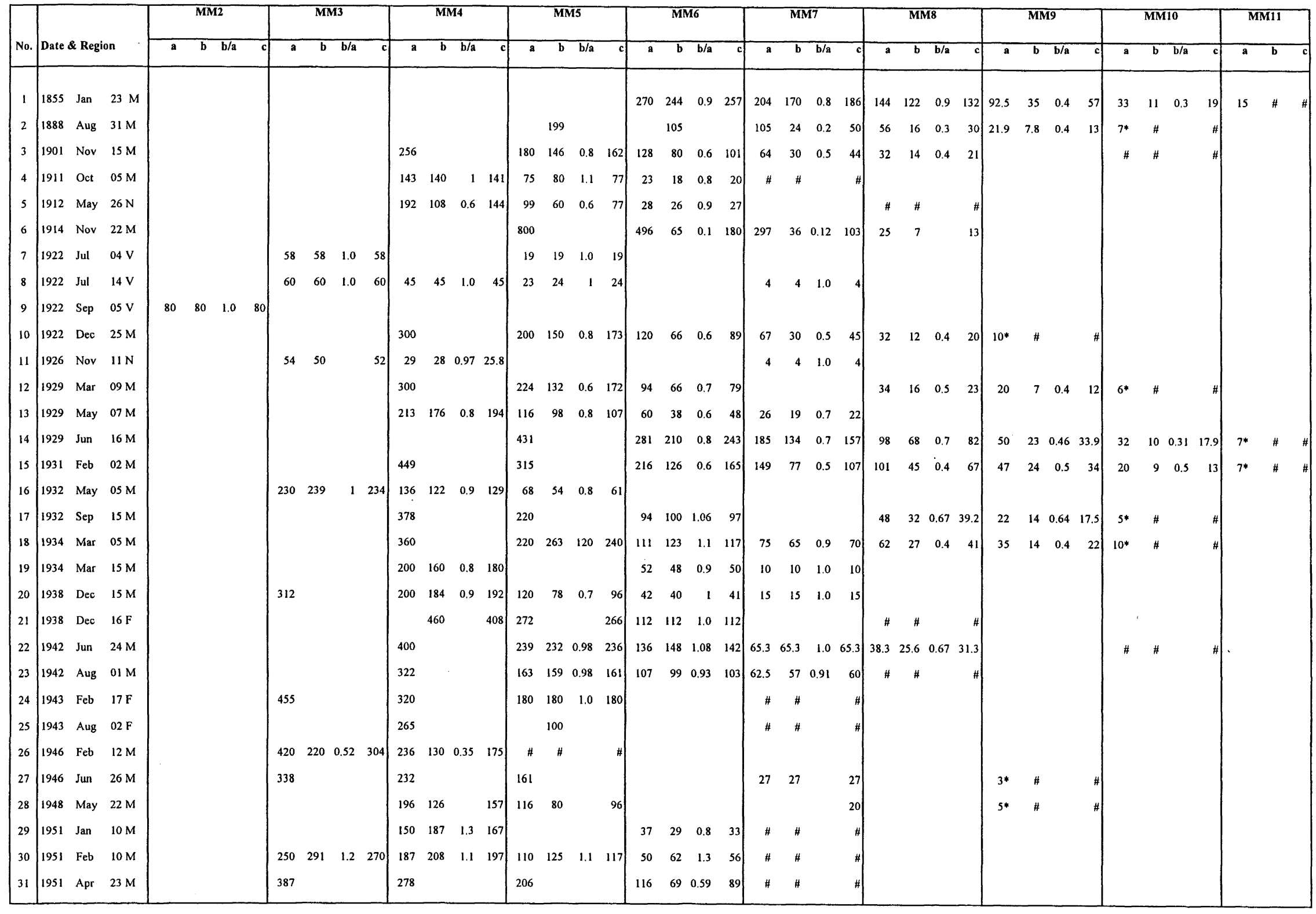




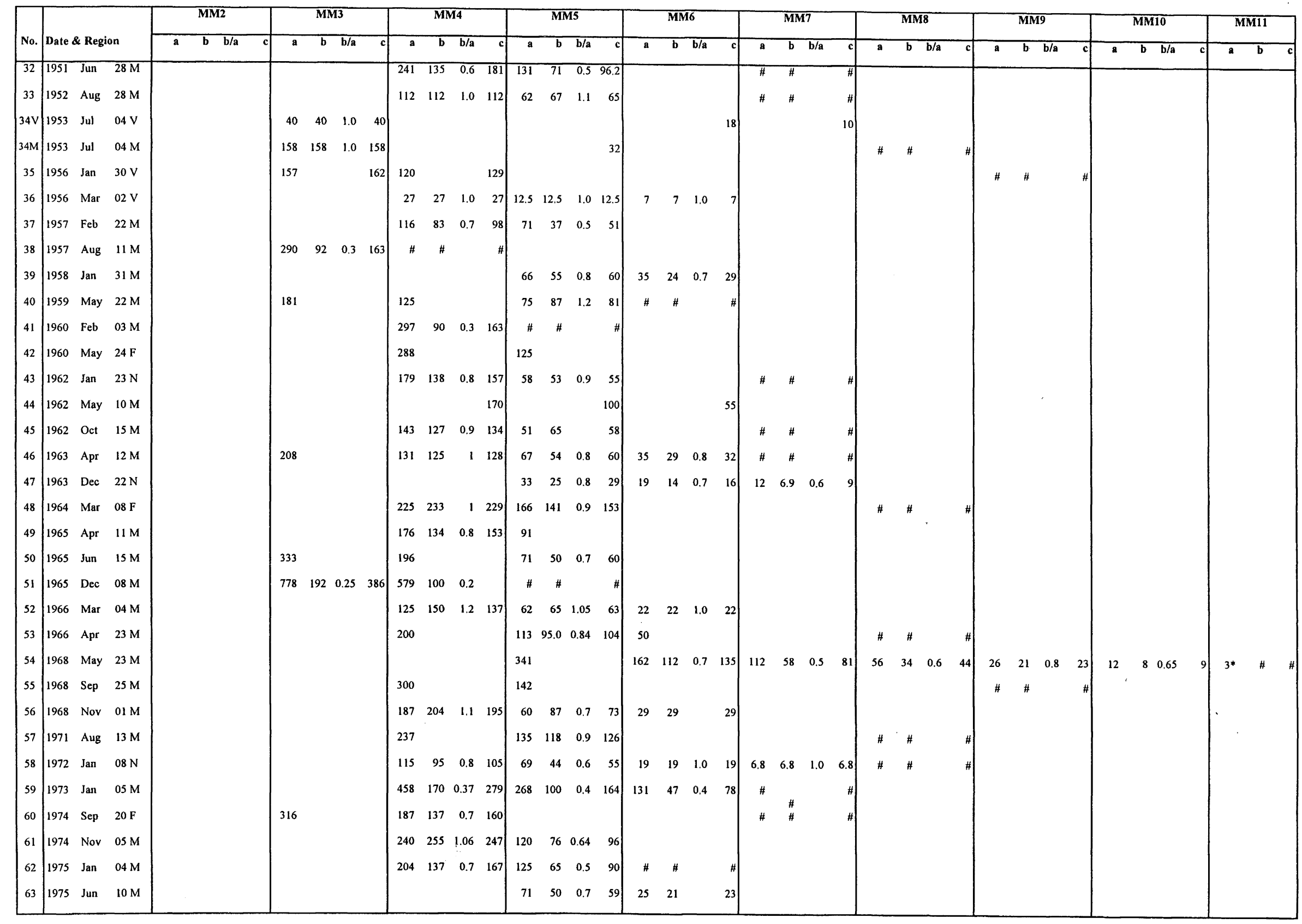




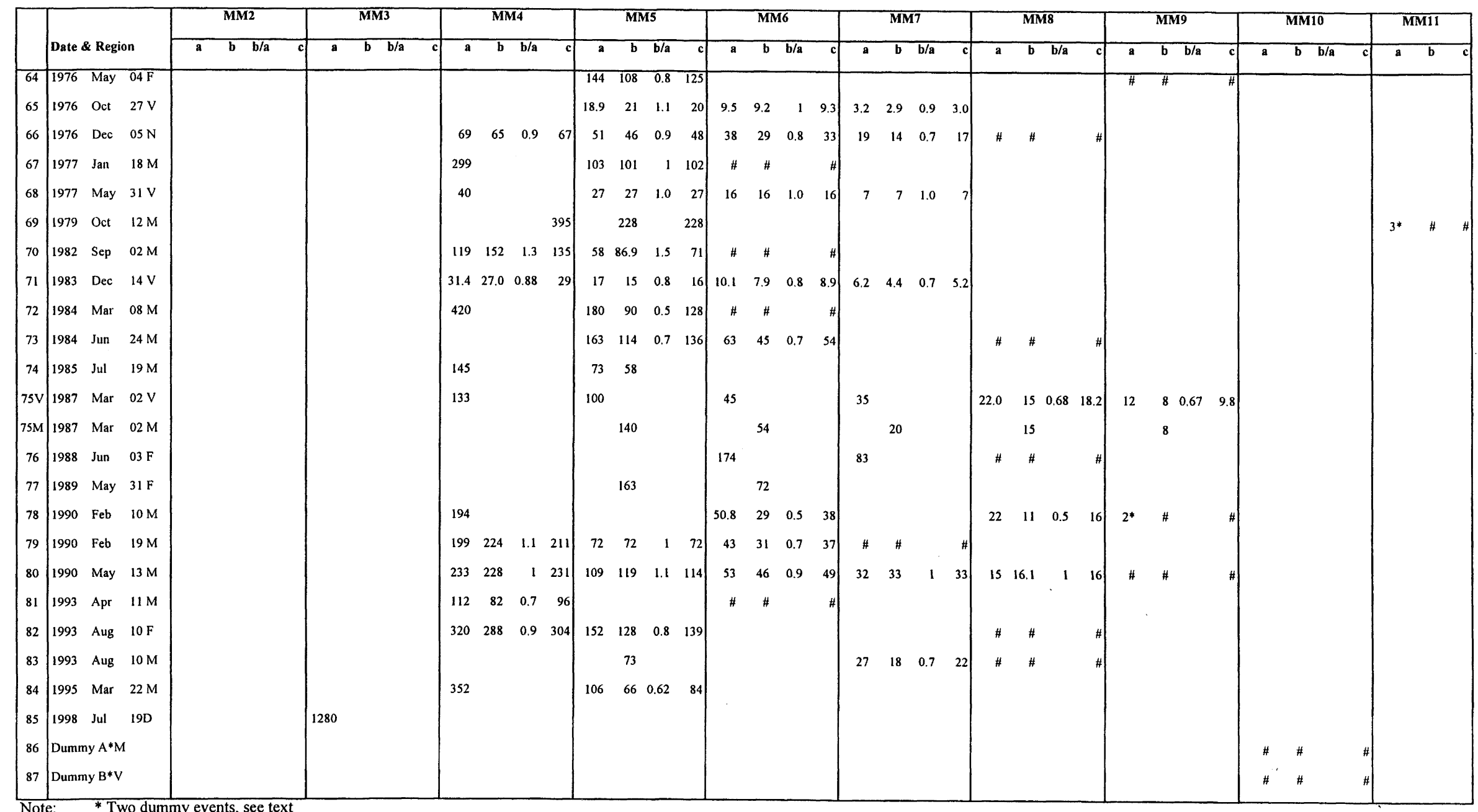


For earthquakes classified as Deep, the strike of the rupture is not relevant to the orientation of the isoseismal patterns. The need to model them separately from shallower events has previously been acknowledged by Smith [2,3]. Earthquakes with sources in the subducting Pacific plate with $h_{C} \geq 70 \mathrm{~km}$ have their isoseismal patterns controlled by the direction of the plate boundary. Figure 5 shows the isoseismal pattern of the largest of the Deep events in the data set, i.e the $M_{W} 7.3$ Bay of Plenty earthquake of 1914 . The source of this event was $300 \mathrm{~km}$ deep with its epicentre near Tauranga [11]. While the strike of the rupture is unknown, the major axis of the isoseismals is oriented at about $\mathrm{N} 40^{\circ} \mathrm{E}$, as is the case for all of the other nine Deep events in the data set. For comparison, the rupture strikes of some of the Deep events are $\theta=332^{\circ}$ (No. 51), $142^{\circ}$ (No. 59) and $288^{\circ}$ (No. 72). For the purposes of this study the strike of the Deep earthquakes has been taken to be parallel to the plate boundary, a value of $\theta=40^{\circ}$ being adopted throughout, and the dimensions $a, b$ and $c$ are related to this strike. As illustrated in Figure 7, a feature of these Deep earthquakes is that their effective surface strike (isoseismal major axis) is constrained by the highly attenuating mantle wedge above the dipping slab, to be in approximately the same location for all events, i.e within about $\pm 30 \mathrm{~km}$ either side of a line passing through about Hicks Bay and Blenheim (line AA in Figures 2 and 7). It is noted that past earthquakes in the same depth range in the subducting Australian plate under Fiordland have not had narrow isoseismals, e.g. the 1965 May $20\left(M_{L} 5.6, h 105 \mathrm{~km}\right)$ and the 1969 January $2\left(M_{L} 5.8, h 135 \mathrm{~km}\right)$ earthquakes [12]. This has occurred because the Australian plate is dipping so steeply that there is little interference by the mantle to seismic waves propagating to the surface.

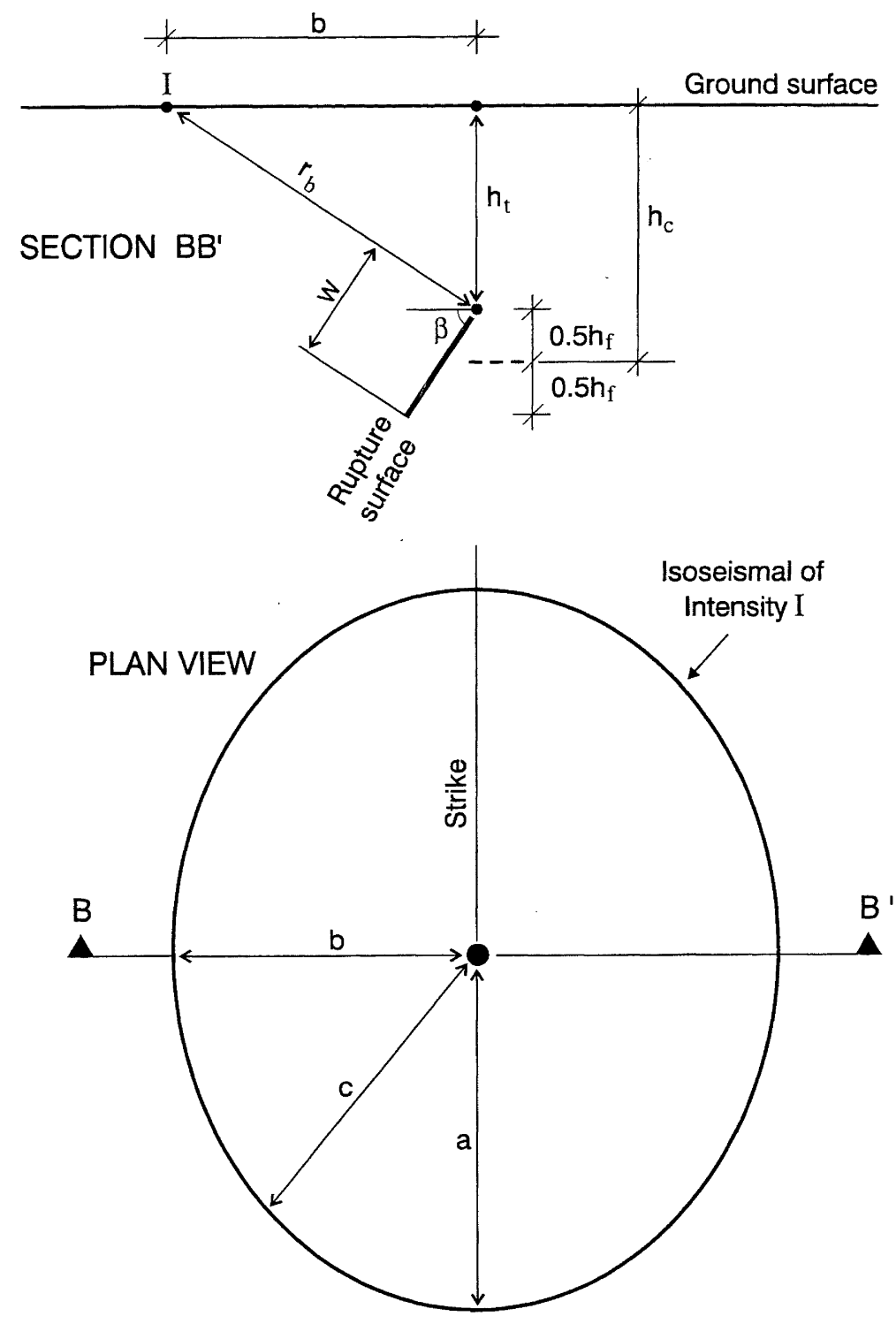

Figure 4: $\quad$ Geometry of the isoseismal distance parameters in relation to the earthquake source rupture. 


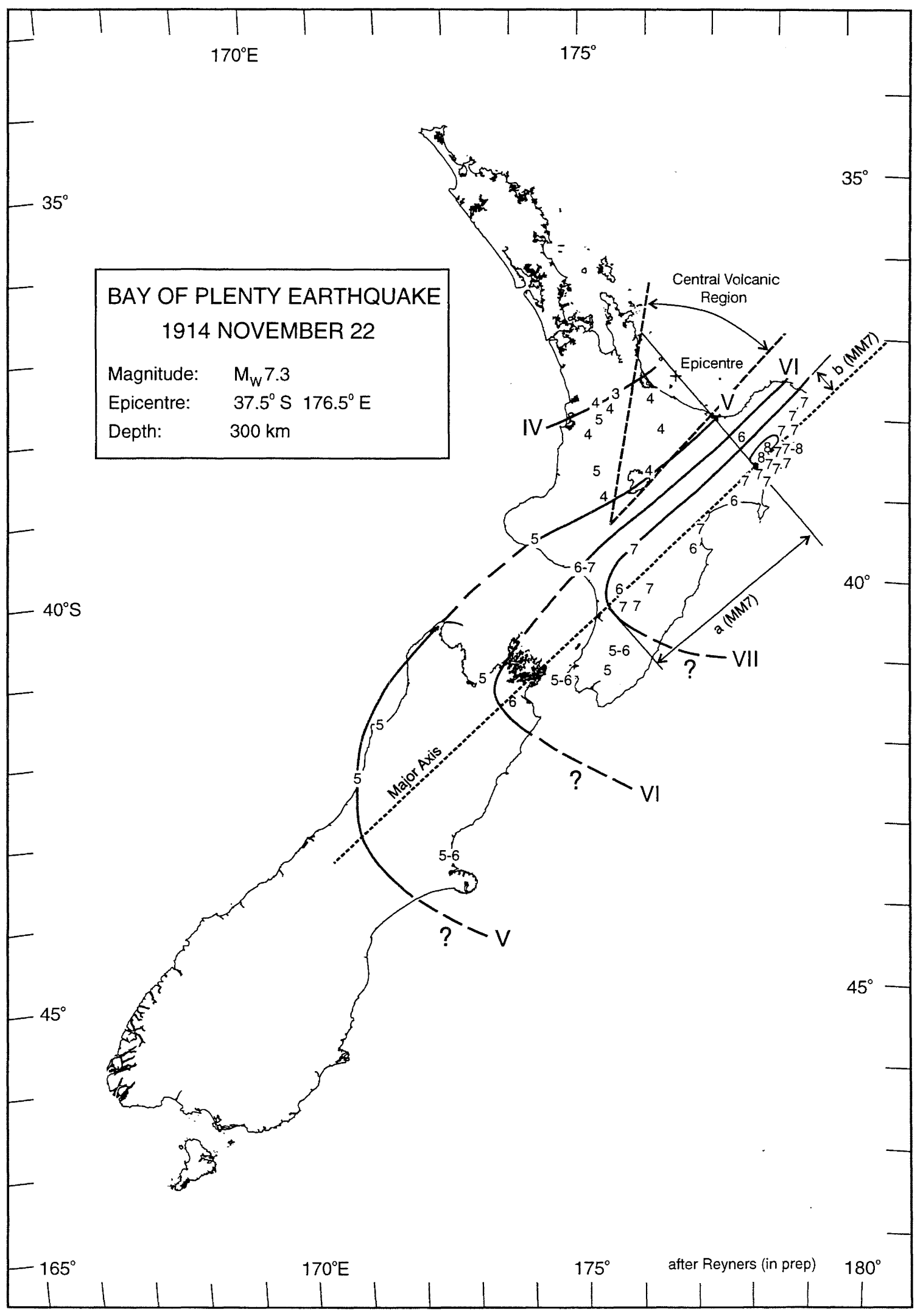

Figure 5: Isoseismal map of the 1914 Bay of Plenty earthquake $\left(M_{W} 7.3, h_{C} 300 \mathrm{~km}\right)$, showing alignment of major axis with tectonic plate boundary, typical of all Deep $\left(h_{C} \geq 70 \mathrm{~km}\right)$ events in the subducting Pacific plate. 
A further important issue relates to the CVR. Distances $a, b$ and $c$ for CVR events were only included if at least 90 percent of the source to isoseismal distance lay within the CVR (Figure 2). For events with sources located outside of the CVR, isoseismal distance data incorporating travel paths across the CVR were omitted, e.g., the MM4 $b$ dimension in Figure 5 was not used.

To illustrate the range of the data in graphical form, the isoseismal source distance data as defined in Equation (1) are plotted against $M_{W}$ in Figure 8, in terms of focal mechanism, intensity, and region. The total numbers of isoseismal source distance data are 300,260 , and 258 , for $r_{a}, r_{b}, r_{c}$ respectively. Of these, three isoseismals are defined by landslides only, i.e. MM10 for Events Nos 1 and 14 and MM9 for Event 12, adapted from maps by Hancox et al. [36]. In addition, in order to constrain the models at the centre of the isoseismal patterns, values of intensity at very small horizontal distances $(a, b, c=0.1 \mathrm{~km})$ were assigned where such intensities were likely to be higher than that of the innermost isoseismal of a given earthquake. This was only done where such intensities could be inferred as an upper bound to the epicentral intensity from the isoseismal map. For example MM11 was assigned at the centre of the 1931 Hawke's Bay earthquake in which MM10 but no MM11 intensities were observed, although MM11 could possibly have just been reached [14]. Also for the 1956 Jan 30 earthquake of $M_{W} 6.3$, MM9 was assigned at its centre which was well offshore in the Bay of Plenty. Such intensities were assigned for 55 of the earthquakes, as indicated by \# symbols in Table 2 . For 11 of these events the $a$ dimension control adopted was larger than $0.1 \mathrm{~km}$, e.g. for Event No. 1 at MM11 $a=15$ was assigned as marked * in Table 2. The two dummy events (Nos. 86 and 87) of $M_{W} 7.0$ and Normal focal mechanisms were assigned MM10 at $a, b, c$ $=0.1 \mathrm{~km}$, on the basis that this data closely matched that modelled for strike-slip events which were well constrained at this magnitude.

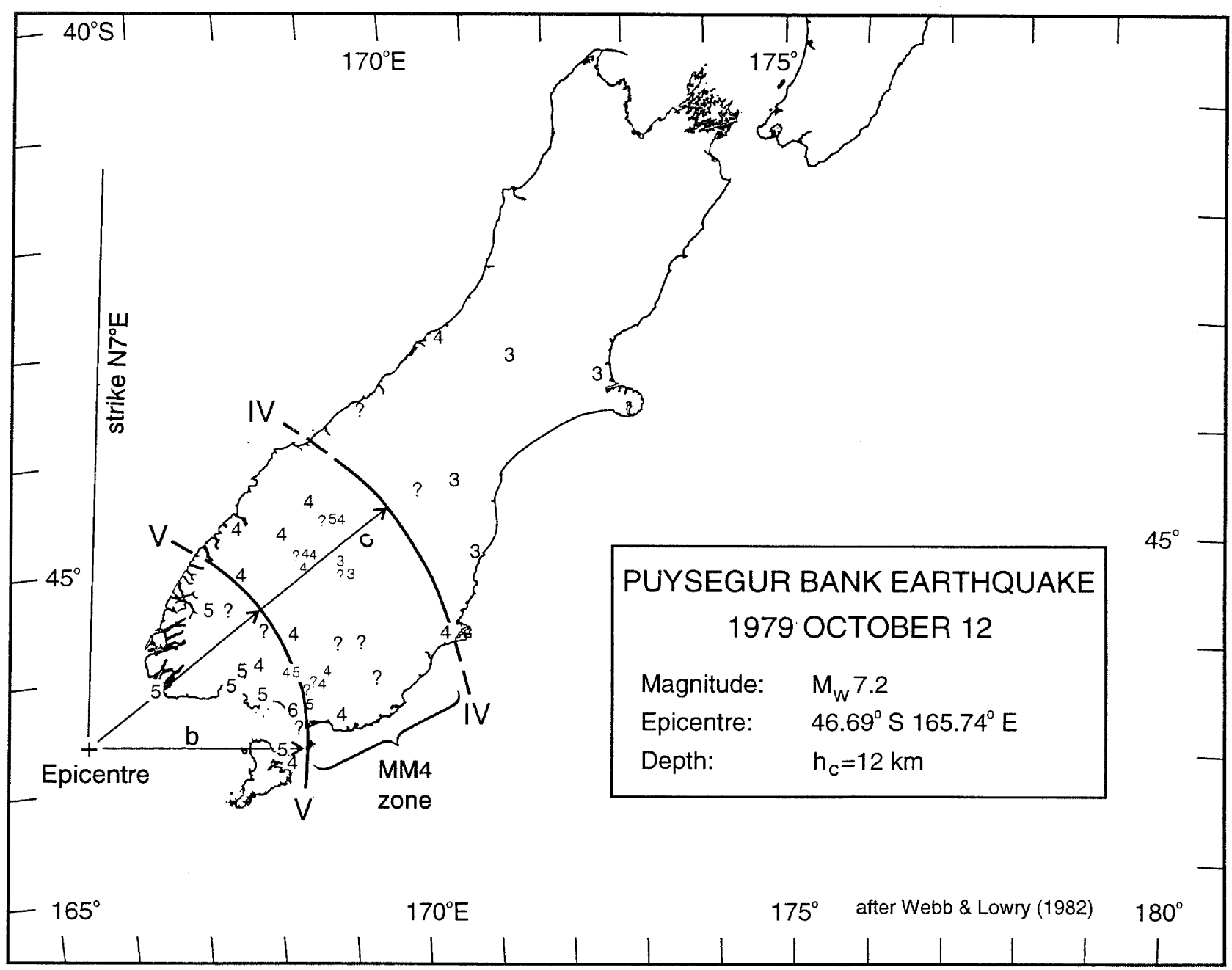

Figure 6: Isoseismal map of the 1979 Puysegur Bank earthquake $\left(M_{W} 7.2, h_{C} 12 \mathrm{~km}\right)$, showing isoseismal geometry in relation to an offshore epicentre. 


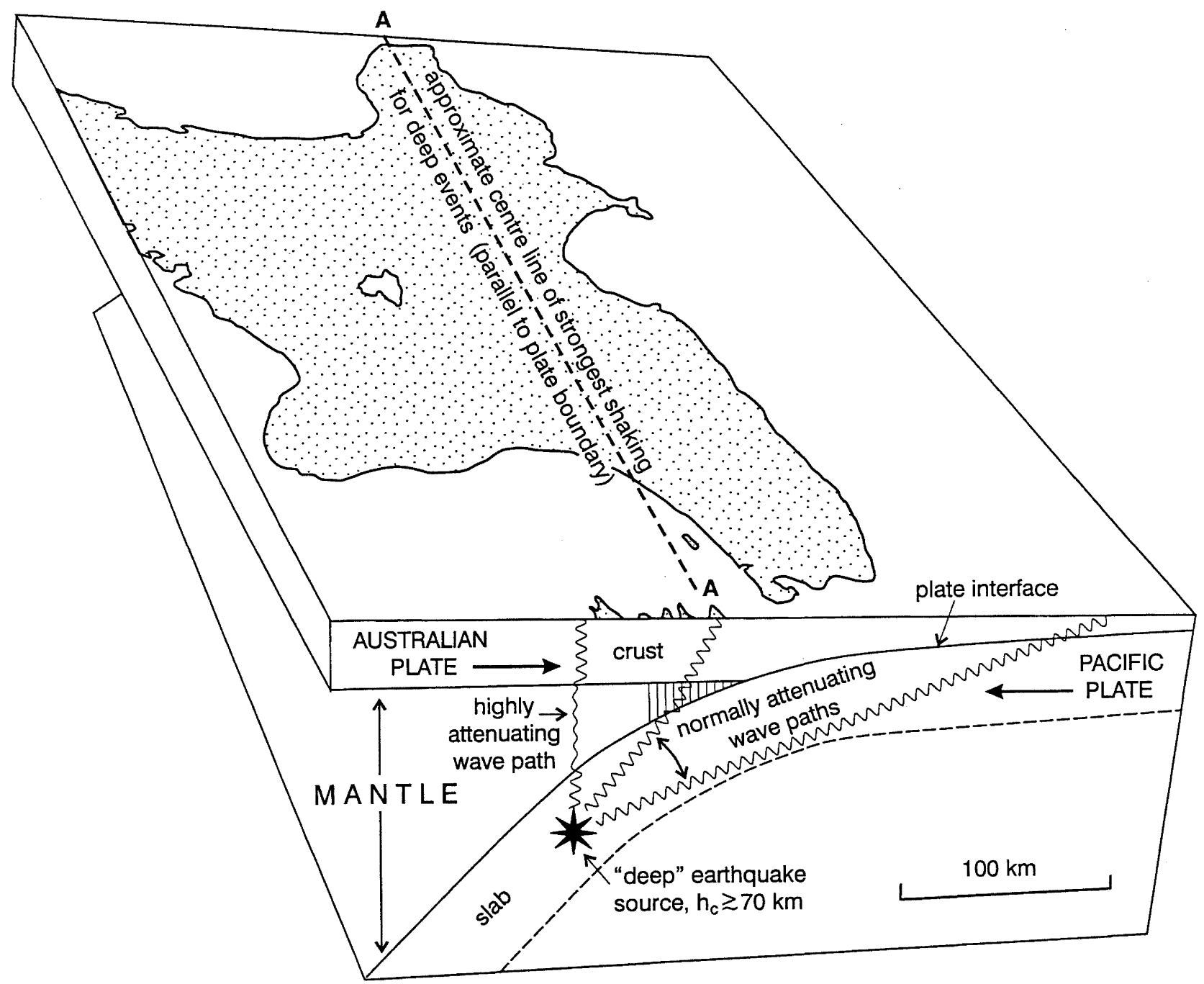

Figure 7: Perspective view of the Australian plate and the subducting Pacific plate under the North Island, with the highly attenuating wedge of mantle protecting surface locations vertically above Deep earthquakes, and constraining the effective "strike" of the isoseismals.

\subsection{DEVELOPMENT OF THE ATTENUATION MODELS}

Attenuation models were developed for subsets of the data by applying multiple regression modelling to the $\mathrm{MM}$ intensity data with moment magnitude and functions of source distance being the primary explanatory variables, but with centroid depth, tectonic region, tectonic type, focal mechanism and rake also being considered for inclusion in the models. Terms were included or excluded based on the Akaike Information Criterion (AIC) statistic [37], given by

$$
A I C=-2 \log L+2 k
$$

where $\log L$ denotes the $\log$ likelihood of the fitted model and $k$ the number of fitted parameters. In the $A I C$ method, a term is included in the model only if it lowers the value of $A I C$, i.e. if the improved fit produces an increase in the likelihood great enough to overcome the penalty of 2 for introducing an extra parameter. Typically a term needs to have an associated $t$-value (ratio of the parameter to its standard error) somewhat greater than one to be included using the $A I C$ criterion.

Separate models were developed for the source distances $r_{a}, r_{b}$ and $r_{c}$. For a given subset of the data, the same model was chosen for each of the distances wherever it was reasonable to do so. This meant an adjustment to the strict application of the AIC method, in which a term of marginal value was included in all three models if it lowered the value of $A I C$ in two of them. In cases where a term clearly improved the fit for one distance, but clearly not for the other two, different models were allowed. 

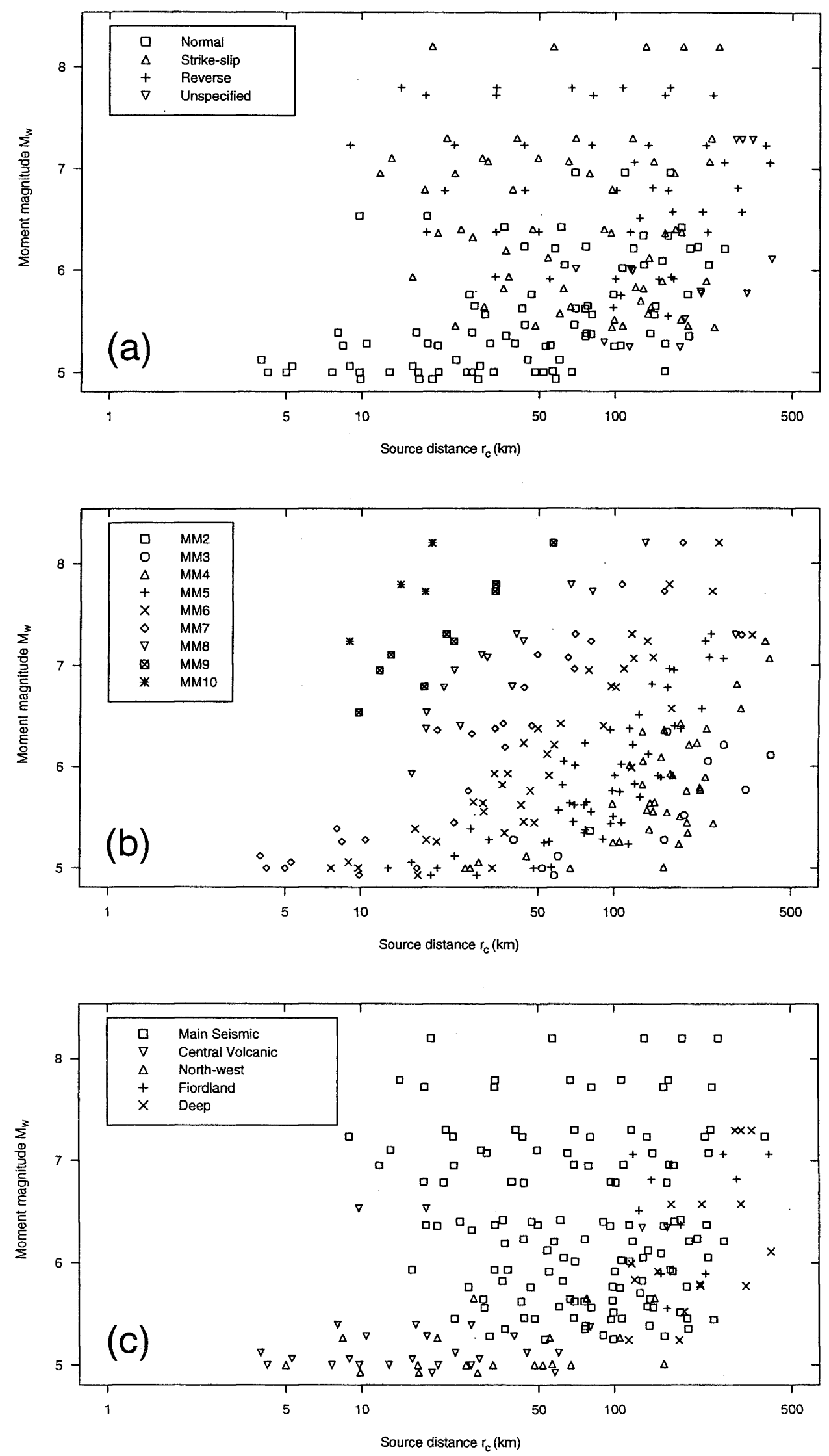

Figure 8: The data for source distance $r_{c}$ plotted against $M_{W}$, showing (a) focal mechanisms, $(b)$ intensities and (c) regions. 
The regression model used was the random effects model [38] in which the error variance is decomposed into a within-earthquake component $\sigma^{2}$ and a between-earthquake component $\tau^{2}$. When considering adequately large subsets of the data, the enhancement of the random effects model to allow for individual earthquake magnitude uncertainties [39] was used. This model allows magnitude data of relatively low quality to be included in the analysis and given the weight that they are due. It extracts the effect of magnitude uncertainties from the between-earthquake component of variance. For class A, B, C and D magnitudes, standard errors of $0.1,0.15,0.3$ and 0.3 respectively were adopted. The value of 0.1 for class $A$ standard errors reflects the very small standard errors published for systematic estimates of $M_{W}$ (e.g., Urhammer et al., [40]). The value of 0.15 for class B is based on an estimate of Dowrick and Rhoades [34] for this class. The value of 0.3 for class $C$ is based on typical errors in Wells and Coppersmith [41] regressions of magnitude on fault rupture length and displacement. The value for class $\mathrm{D}$ is based on the authors' judgement.

A nonlinear function of source distance, denoted $\log D$, was applied in the regression modelling. It has the form

$$
\log D=\log _{10}\left[\left(r^{2}+d^{2}\right)^{1 / 2}\right]
$$

where $r=r_{a}, r_{b}$ or $r_{c}$ and $d$ is a parameter to be estimated. The use of $\log D$ as a regression term rather than $\log r$ improved the fit to the near source attenuation intensity data, and a non-zero value of $d$ proved to be useful for all subsets except the deep earthquakes considered by themselves.

Indicator variables were used to include the effects of factors, such as focal mechanism, tectonic type and tectonic region, in the regression models. For a given level $L$ of a factor $F$, the indicator variable $\delta_{L}$ is defined by $\delta_{L}=1$ if $F=L$ and 0 otherwise.

\subsection{DISCUSSION OF THE ATTENUATION MODELS}

\subsection{Functional form}

The random effects models fitted are of the form

$$
I=\alpha+\beta M_{W}+\gamma \log D+\sum_{l=1}^{m}+\theta_{l} x_{l}+\zeta+\varepsilon
$$

where $I$ is Modified Mercalli intensity, $M_{W}$ is moment magnitude, $\log D$ is as defined above, $x_{l}, l=1 \ldots m$ are additional regression terms, $\zeta$ is a normally distributed random variable which is determined by the earthquake and has variance $\beta^{2} s^{2}+\tau^{2}$ where $s$ is the earthquake magnitude standard error, and $\varepsilon$ is a normally distributed random variable with mean zero and variance $\sigma^{2}$. The parameters to be estimated are $d, \alpha, \beta, \gamma, \theta_{l}$, $l=1 \ldots m, \tau$ and $\sigma$.

Models were developed for three different subsets of the data, namely:

(1) all data with known focal mechanisms, excluding only Deep events;

(2) the Main Seismic Region, excluding Deep earthquakes;

(3) Deep earthquakes.
Magnitude uncertainties were included for subsets (1) and (2), but for subset (3) the number of data were insufficient to support the fitting of the uncertain magnitudes model. The parameter estimates, standard errors, residual standard deviations, and the number of data for each model are given in Tables 3-5.

\subsection{Goodness of fit and robustness}

The residual standard deviation of the models (calculated as $\left.\left(\tau^{2}+\sigma^{2}\right)^{1 / 2}\right)$ is typically about 0.5 units of MM Intensity (listed in Tables 3-5), with $\tau$ being consistently less than $\sigma$. A small value of $\tau$ limits the extent to which the inclusion of further variables which are functions of the earthquake source, such as focal mechanism or tectonic type, can improve the fit, because such terms can serve only to reduce $\tau$ and not $\sigma$.

The standard errors of the parameters provide insight into how well the models are determined. These values are given in Tables 3-5. Overall, along with the residual standard deviation, they show that Models 1 and 2 are more robust than Model 3, and when considered as coefficients of variation (c.o.v. = Standard Error divided by Estimate) they indicate the robustness of the individual parameters. For example the least robust term in Model 1 is $h_{C}$ (direction $a$ ) which has c.o.v. $=0.54$, with the c.o.v values for the other terms ranging down to as little as 0.03 (for $\log D$ ).

One measure of the goodness of fit of the models can be gained by examining plots of the residuals against fitted variables, where the residuals are defined as the difference between the actual and fitted value of $I$, to test if the assumptions of linearity are approximately satisfied. This has been done exhaustively for all models and in no case is there strong evidence of a trend in the relation between residuals and fitted values of $I$, or between the residuals and regression variables. Examples of such residual plots are given in Figure 9. The four plots for Model 2 (Main Seismic Region) show the model fitting the data well, with the residuals spread reasonably symmetrically about zero over the full ranges of distance, magnitude and depth as well as fitted intensity. Figure 9 also shows residuals for fitted intensities in the direction of strike for the CVR, North-west region, Fiordland and Deep earthquakes. These plots show that these four subsets are reasonably well fitted by the respective models.

It is of much interest to examine the fit of the models to the data from individual earthquakes, especially in cases where more than one different model may be applied to a particular earthquake. Examples of such fits are presented in Figures 10 and 11. Figure 10 shows how Models 1 and 2 fit the data of four of the largest $\left(M_{W}\right.$ 7.1-7.8) shallow Main Seismic Region earthquakes. Three of these earthquakes are Crustal Reverse events, while the other occurred in the Slab $\left(h_{c}=40 \mathrm{~km}\right)$ with a Normal focal mechanism. All of these events have several data in both the $a$ and $b$ directions so that the fit with distance for each event can be seen individually. The fit in all cases is good, the residuals of most data points being less than the typical standard deviation of 0.5 of an intensity unit. Note that the MM10 data point for the 1929 earthquake is an estimate based on landslide data only. It is also of interest to observe that for these Main Seismic Region events the three models predict very similar intensities over the full distance range ( $a=1$ to $500 \mathrm{~km})$. 
Table 3: Model 1 "Focal mechanisms"

Parameter Estimates and standard errors in random effects regression models of MM Intensity (allowing for magnitude uncertainties) using only earthquakes with known mechanisms and excluding the Deep region. Model selection was based on the AIC statistic.

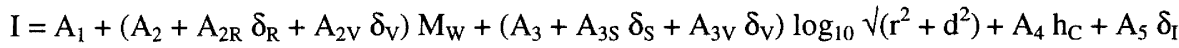

$$
\begin{aligned}
& \text { where } \quad \delta_{\mathrm{R}}=1 \text { for Reverse focal mechanisms } \\
& 0 \text { for all other events } \\
& \delta_{\mathrm{S}}=1 \text { for Strike-slip focal mechanisms } \\
& 0 \text { for all other events } \\
& \delta_{\mathrm{V}}=1 \text { for CVR events } \\
& 0 \text { for all other events } \\
& \delta_{\mathrm{I}}=1 \text { for interface events } \\
& 0 \text { for all other events }
\end{aligned}
$$

\begin{tabular}{|c|c|c|c|c|c|c|}
\hline $\mathbf{A}_{1}$ & 4.87 & 0.46 & 4.97 & 0.42 & 4.92 & 0.40 \\
\hline$A_{2}$ & 1.25 & 0.07 & 1.03 & 0.07 & 1.12 & 0.07 \\
\hline$A_{2 R}$ & 0.048 & 0.022 & 0.058 & 0.020 & 0.061 & 0.019 \\
\hline$A_{2 v}$ & 0.21 & 0.06 & 0.18 & 0.06 & 0.20 & 0.05 \\
\hline $\mathbf{A}_{3}$ & -3.77 & 0.09 & -3.39 & 0.09 & -3.54 & 0.09 \\
\hline $\mathbf{A}_{3 \mathbf{S}}$ & 0.16 & 0.06 & 0.23 & 0.06 & 0.25 & 0.06 \\
\hline$A_{3 v}$ & -1.47 & 0.23 & -1.35 & 0.23 & -1.32 & 0.21 \\
\hline $\mathbf{A}_{4}$ & 0.0083 & 0.0041 & 0.015 & 0.004 & 0.013 & 0.004 \\
\hline$A_{5}$ & -0.68 & 0.23 & -0.41 & 0.18 & -0.63 & 0.19 \\
\hline d & 9.63 & 0.95 & 5.74 & 0.61 & 7.30 & 0.68 \\
\hline$\tau$ & 0.26 & 0.02 & 0.21 & 0.02 & 0.20 & 0.02 \\
\hline$\sigma$ & 0.37 & 0.01 & 0.36 & 0.01 & 0.34 & 0.01 \\
\hline dual & 1. 0.45 & & 0.42 & & 0.39 & \\
\hline & 262 & & 231 & & 230 & \\
\hline & 73 & & 74 & & 72 & \\
\hline
\end{tabular}

Distance $\quad$ a $\quad b \quad c$

Notes: $\quad * * \quad \mathrm{~N}=$ Number of source-to-isoseismal distance data

* $\quad$ Neq $=$ Number of earthquakes

Figure 11 shows how various of the models fit the data of four small to medium-sized $\left(M_{W}\right.$ 5.3-6.6) earthquakes from four different regions. Our preferred models fit the data well in all four events. Event $58\left(M_{W} 5.3, h_{C} 7\right.$, Normal) from the Northwest Sub-region is seen to be fitted well by the Main Seismic Region Models 1 and 2 and not Model 1 volcanic, i.e. this event has the attenuation characteristics of the Main Seismic Region and not of the CVR. Event 80, (1990 Weber II) shows that the data of an $M_{W} 6.4, h_{C} 13$, Reverse Main Seismic Region earthquake is well fitted by Models 1-2. Event 59 (1973 Central Nth Island) $M_{W} 6.6, h_{C} 149$, is typical of Deep events (Figure 5), with data from both direction $a$ and $b$ being fitted reasonably well by Model 3. The typical high attenuation of the CVR earthquake in Figure 11 (Event 68) is seen to be well modelled by Model 1 (Volcanic), but not by the model for Normal mechanism Main Seismic Region events.

Similar plots to those shown in Figures 10 and 11 have been made for all events in the database, an examination of which shows the fit to the preferred model to be satisfactory throughout. As is consistent with the functional form of the models, there is no sign either of magnitude saturation effects or that the attenuation rate varies with magnitude. 
Table 4: Model 2 "Main Seismic region"

Parameter Estimates and standard errors in random effects regression models of MM Intensity (allowing for magnitude uncertainties) using data from the main seismic region (including the Northwest and Fiordland sub-regions) and excluding Deep earthquakes. Model selection was based on the AIC statistic.

$I=A_{1}+A_{2} M_{W}+A_{3} \log _{10} \sqrt{ }\left(r^{2}+d^{2}\right)+A_{4} h_{C}+A_{5} \delta_{C}$

where $\quad \delta_{\mathrm{C}}=1$ for Crustal events

0 for all other events

Distance

a

b

$c$

Term Estimate std.Err. Estimate std.Err. Estimate std.Err.

$\begin{array}{lclllll}\mathrm{A}_{1} & 4.25 & 0.46 & 4.20 & 0.43 & 4.12 & 0.42 \\ \mathrm{~A}_{2} & 1.28 & 0.07 & 1.11 & 0.06 & 1.18 & 0.06 \\ \mathrm{~A}_{3} & -3.73 & 0.09 & -3.27 & 0.09 & -3.46 & 0.09 \\ \mathrm{~A}_{4} & 0.017 & 0.005 & 0.021 & 0.005 & 0.021 & 0.005 \\ \mathrm{~A}_{5} & 0.54 & 0.13 & 0.31 & 0.13 & 0.47 & 0.13 \\ \mathrm{~d} & 10.05 & 1.10 & 5.65 & 0.70 & 7.31 & 0.75 \\ \tau & 0.24 & 0.02 & 0.20 & 0.03 & 0.21 & 0.02 \\ \sigma & 0.39 & 0.02 & 0.40 & 0.02 & 0.36 & 0.02\end{array}$

Residual s.d. 0.46

$\mathrm{N}^{*}$ * 236

0.44

Neq*

64

210

0.41

65

205

63

Notes: ** and * see Table 3.

Table 5: Model 3 "Deep region"

Parameter Estimates and standard errors in random effects regression models of MM Intensity using Deep earthquakes under the main seismic region only. Model selection was based on the AIC statistic.

$I=A_{1}+A_{2} M_{W}+A_{3} \log _{10} r+A_{4} h_{C}$

Distance

a

b

c

Term Estimate Std.Err. Estimate std.Err. Estimate std.Err.

$\begin{array}{cclclll}\mathrm{A}_{1} & 4.00 & 1.74 & 10.08 & 3.78 & 5.60 & 2.96 \\ \mathrm{~A}_{2} & 1.63 & 0.35 & 1.77 & 0.58 & 1.83 & 0.51 \\ \mathrm{~A}_{3} & -4.03 & 0.34 & -8.02 & 1.11 & -5.56 & 0.62 \\ \mathrm{~A}_{4} & 0.0044 & 0.0029 & 0.012 & 0.006 & 0.0058 & 0.0047 \\ \tau & 0.18 & 0.12 & 0.38 & 0.08 & 0.34 & 0.07 \\ \sigma & 0.49 & 0.06 & 0.52 & 0.07 & 0.44 & 0.06\end{array}$

$\begin{array}{lccc}\text { Residual s.d. } & 0.52 & 0.64 & 0.56 \\ \mathrm{~N}^{* *} & 32 & 25 & 24 \\ \text { Neq* } & 11 & 10 & 10\end{array}$

Notes: $* *$ and $*$ see Table 3 . 
Model 2, Main Seismic region

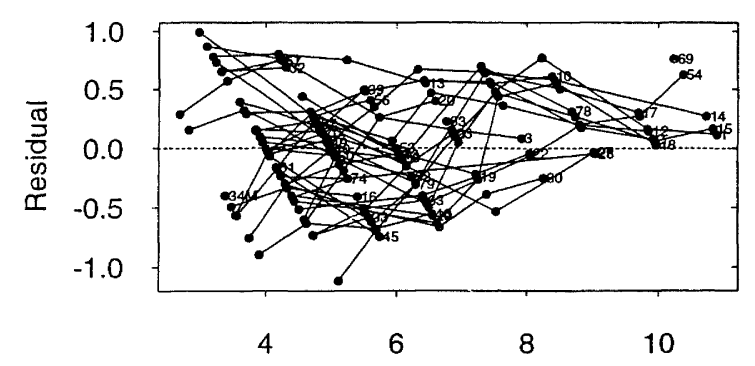

Fitted MM Intensity

Model 2, Main Seismic region

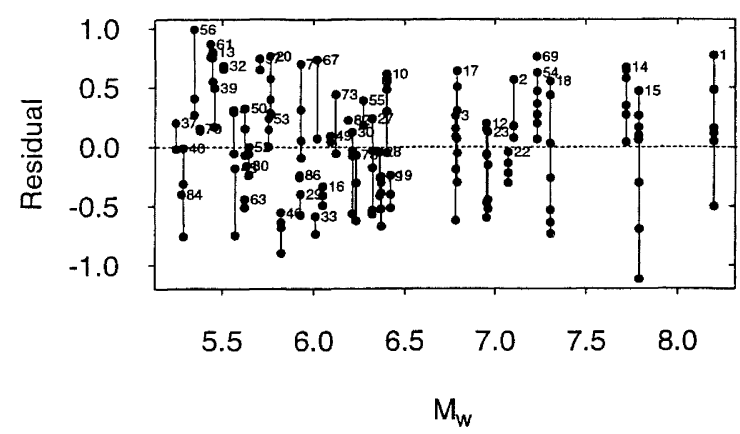

Model 1, Central Volcanic region

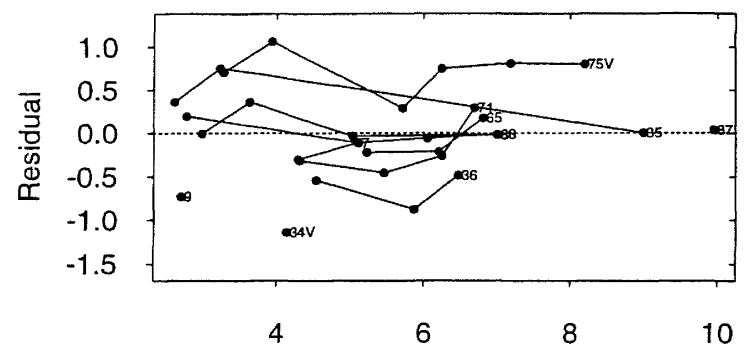

Fitted MM Intensity

Model 2, Fiordland region

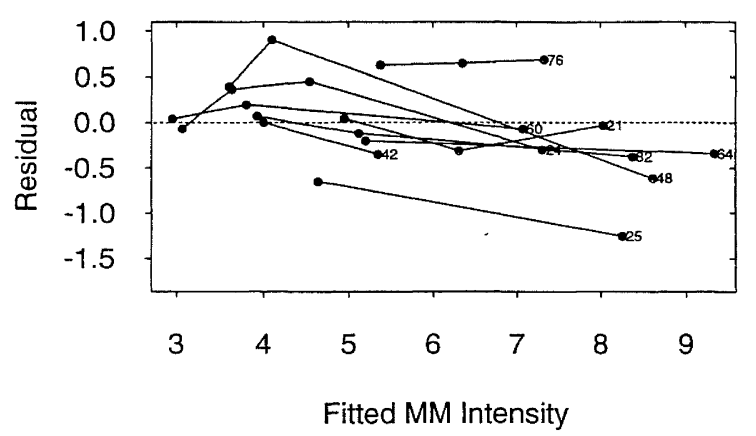

Model 2, Main Seismic region

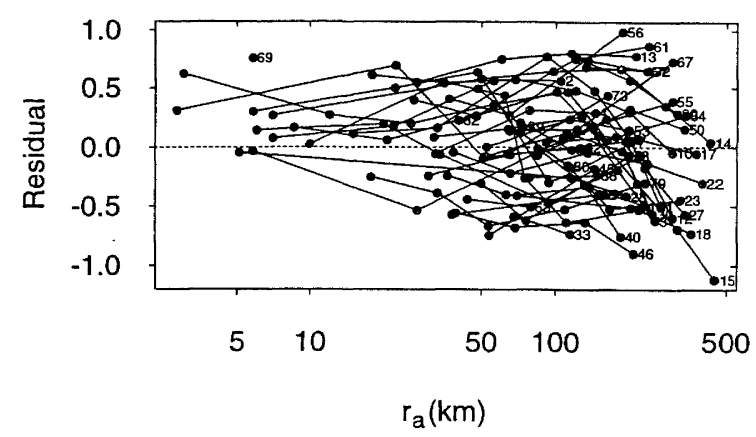

Model 2, Main Seismic region

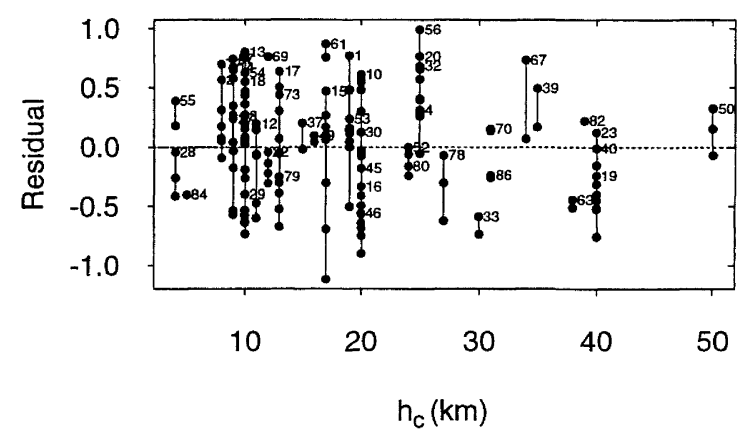

Model 2, North-west region

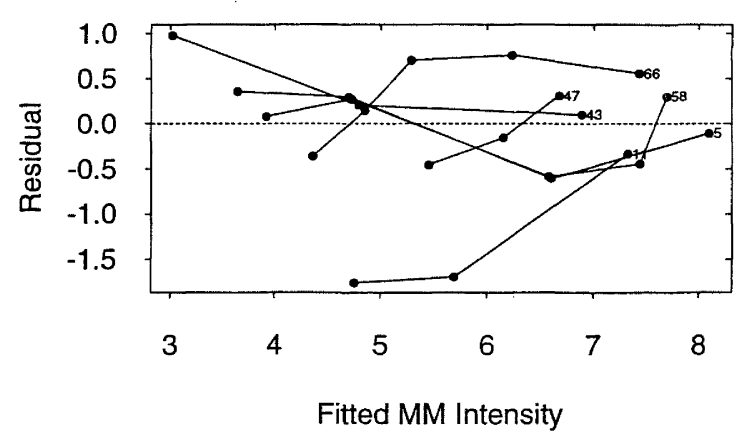

Model 3, Deep region

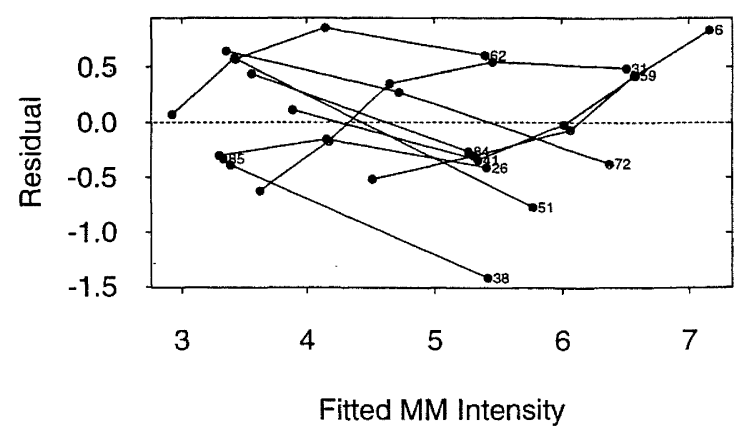

Figure 9: Plots of residuals for the Main Seismic Region using Model 2 (considering fitted intensity, $r_{a}, M_{W}$ and $h_{C}$ ), and residuals of fitted intensities for Models 1-3 (considering the CVR, Deep events the North-west region and Fiordland). The data for individual earthquakes are connected by lines and identified with the Event Number. 
$14: 1929$ Jun 16 Mw 7.72 hc 9 M R

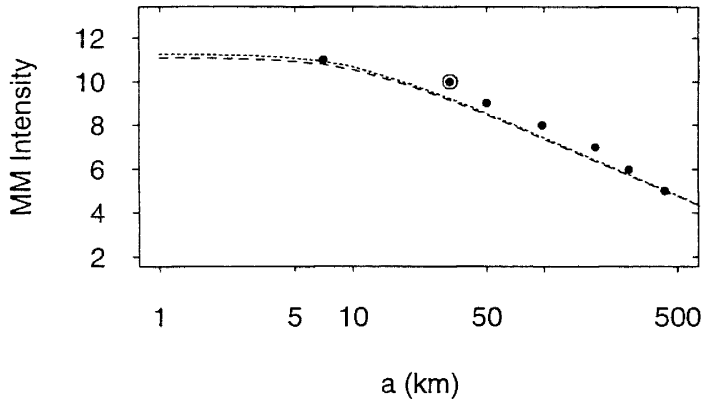

$15: 1931$ Feb 2 Mw 7.79 hc 17 M R

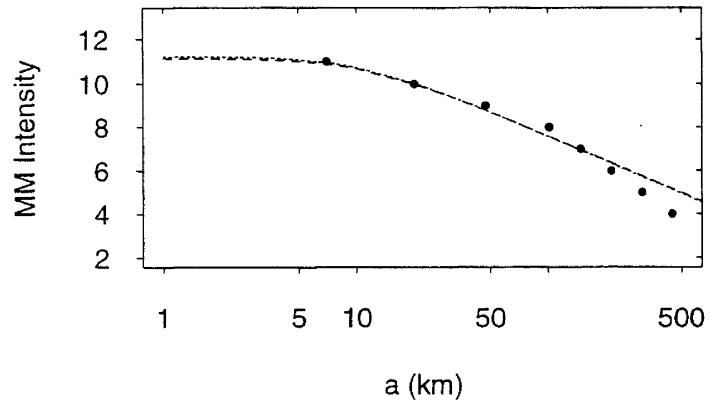

23 : 1942 Aug 1 Mw 6.96 hc 40 M N

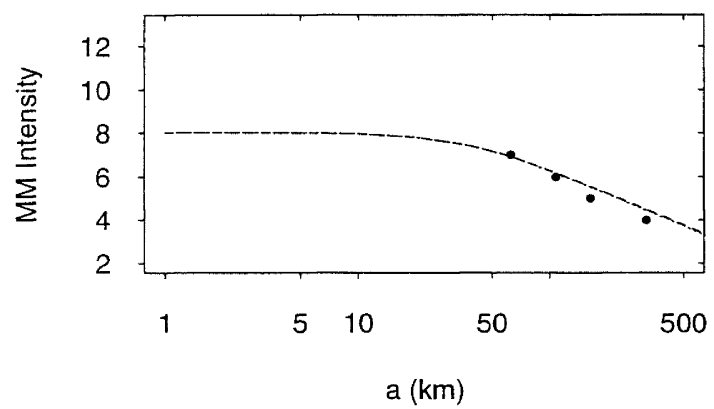

54 : 1968 May 23 Mw 7.23 hc 10 M R

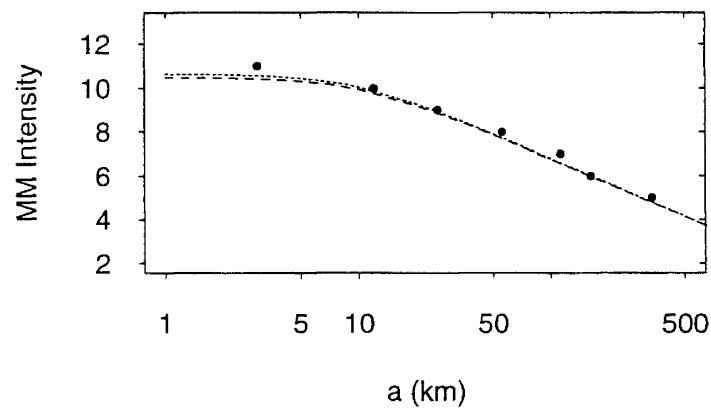

Model 1,
14 : 1929 Jun 16 Mw 7.72 hc 9 M R

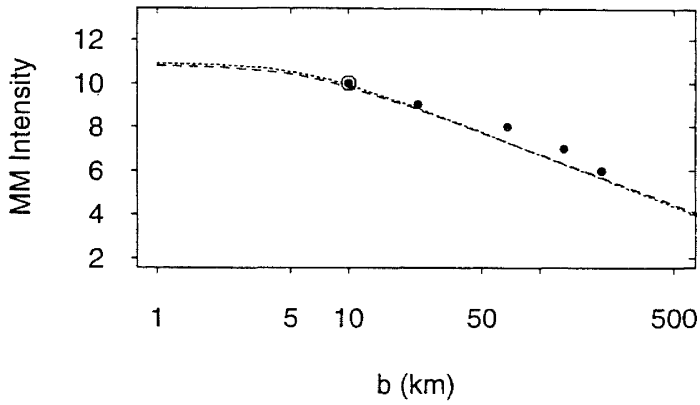

$15: 1931$ Feb 2 Mw 7.79 hc 17 M R

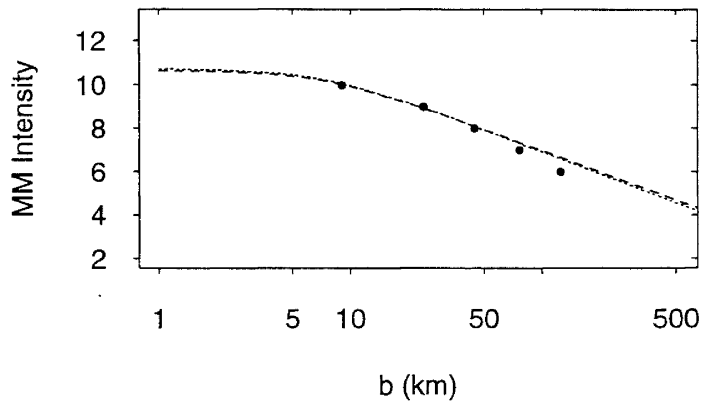

23 : 1942 Aug $1 \mathrm{Mw} 6.96$ hc $40 \mathrm{M} \mathrm{N}$

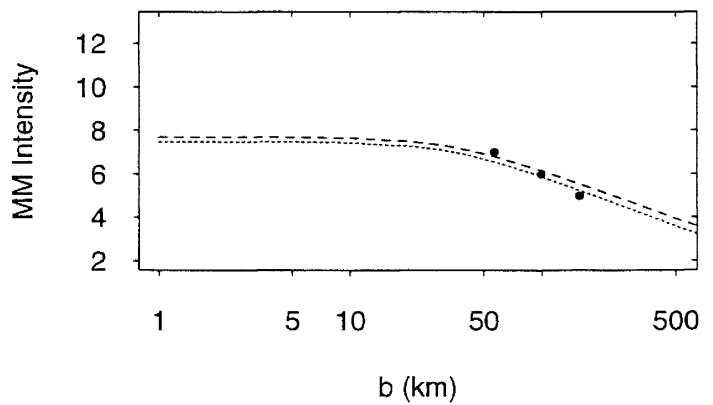

54 : 1968 May 23 Mw 7.23 hc 10 M R

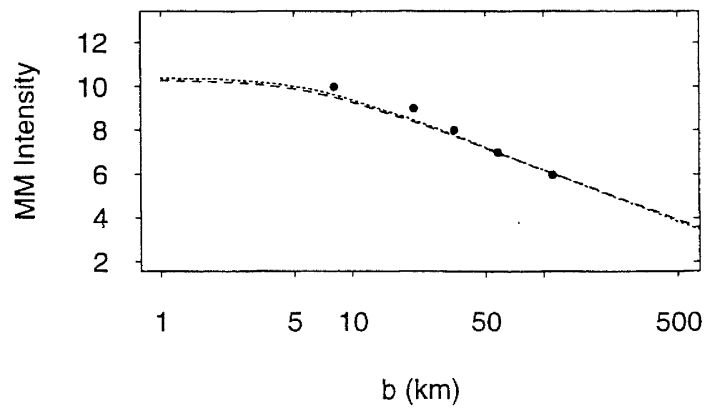

Model 2

Figure 10: $\quad$ Plots of Models 1 and 2 against $a$ and $b$ data for four large earthquakes, $M_{W} 7-7.8, h_{C} 9-40 \mathrm{~km}$. The header to each plot starts with event number and ends with region $(M=$ Main Seismic Region) followed by focal mechanism $(R$ or $N)$. For Event 14 the MM10 distance data (circled) were estimated from landslides only. 
$58: 1972$ Jan 8 Mw 5.26 hc 7 N N 58 : 1972 Jan 8 Mw 5.26 hc 7 N N
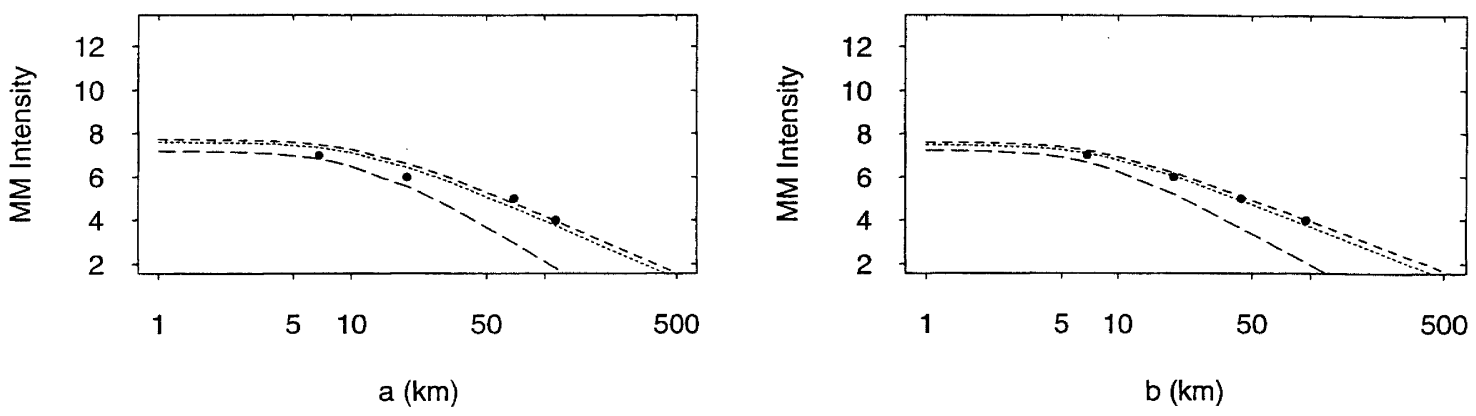

80 : 1990 May 13 Mw 6.37 hc 13 M R

$80: 1990$ May 13 Mw 6.37 hc 13 M R
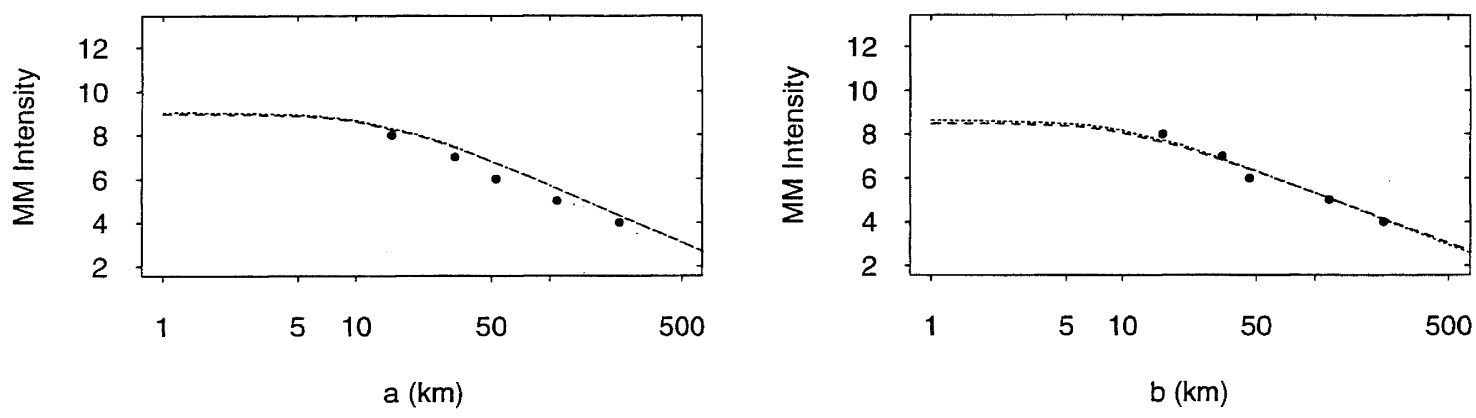

59 : 1973 Jan 5 Mw 6.57 hc 149 D R

59 : 1973 Jan 5 Mw 6.57 hc 149 D R
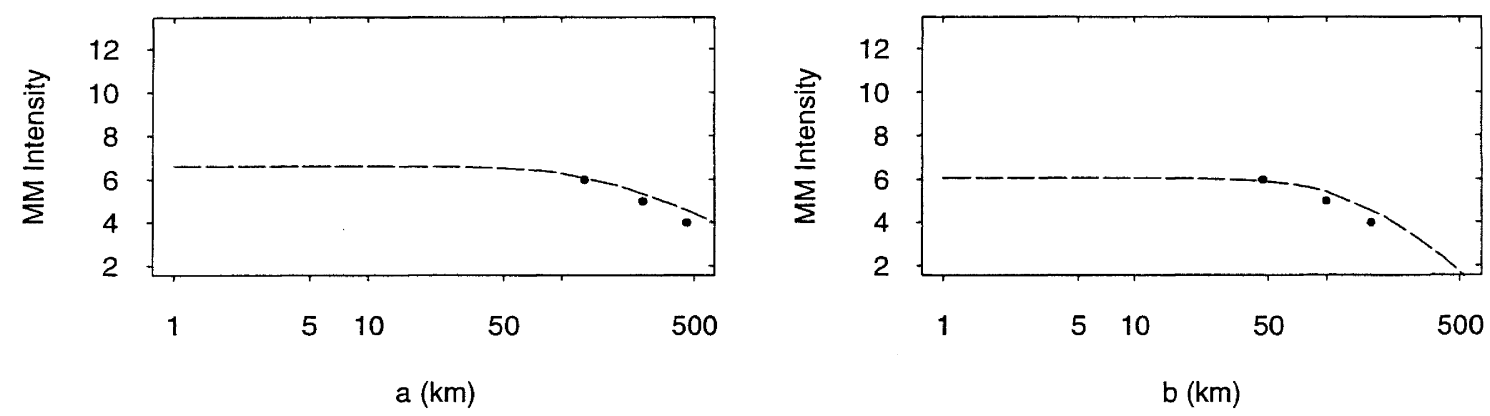

68 : 1977 May 31 Mw 5.39 hc 6 V N

68 : 1977 May 31 Mw 5.39 hc 6 V N
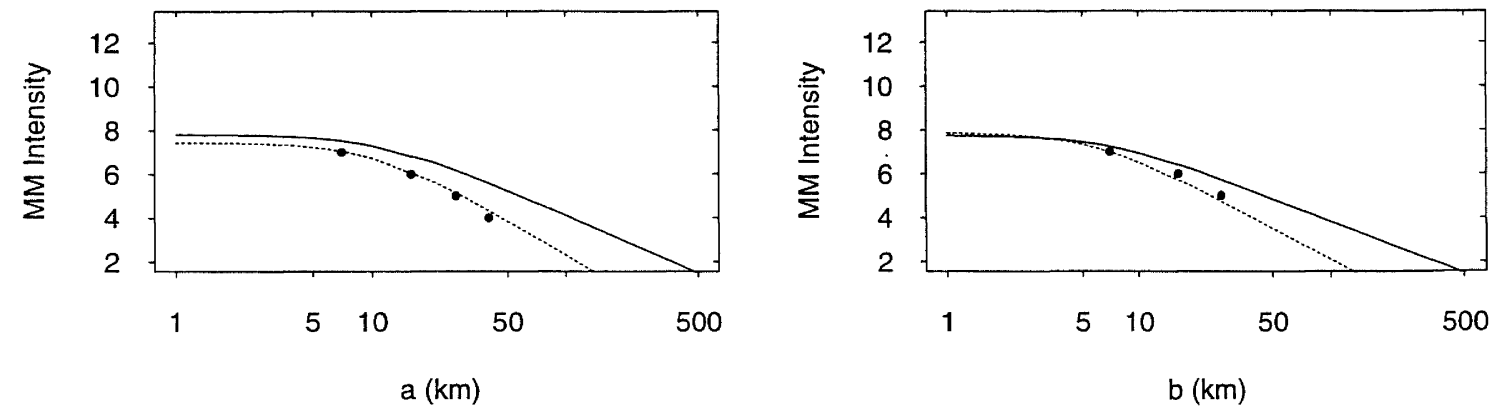

Model 1,

Model 2,

Model 3

Model 1 Volcanic,

Model 1 Normal

Figure 11: Plots of Models 1-3, where appropriate, against a and b data for events of $M_{W}$ 5.3-6.6 from four regions, Main Seismic Region (M), North-west (N), CVR (V) and Deep earthquakes (D). 
A limitation of all of the models is that they only apply within the range of the data used in fitting them. Outside of that range, the errors are likely to be much increased and systematic. Except for the Main Seismic Region, the range of the existing data within any particular region is quite restricted. For example, the largest magnitudes and the number $\left(\mathrm{N}_{\mathrm{eq}}\right)$ of events in some of the data sets are:

$\begin{array}{llll}\text { - } & \text { MSR Crustal } & M_{W} 8.2, & \mathrm{~N}_{\mathrm{eq}} 51 \text { (+ Dummy } \\ & M_{W} 7.0 \text { Normal) } & & \\ \text { - } & \text { MSR Slab (excl. Deep) } & M_{W} 7.0, & \mathrm{~N}_{\mathrm{eq}} 19 \\ \text { - } & \text { Deep } & M_{W} 7.3, & \mathrm{~N}_{\mathrm{eq}} 11 \\ \text { - } & \text { CVR } & M_{W} 6.5, & \mathrm{~N}_{\mathrm{eq}} 10 \text { (+ Dummy } \\ & \left.M_{W} 7.0\right) & & \end{array}$

Finally it is noted that the two dummy events, with intensity data at source only, were found to have the desired effect of controlling the near source modelling of large very shallow Normal events in the CVR and Main Seismic Region, without perturbing the fit of the models to the data.

\subsection{Effect of depth}

Centroid depth $h_{C}$ was considered as a candidate explanatory variable and emerged as a significant term with a positive coefficient in all models. When the Deep earthquakes $\left(h_{C} \geq 70\right.$ $\mathrm{km}$ ) are considered on their own (Model 3), the coefficients for $h_{C}$ for modelling $a, b$ and $c$ are all substantially smaller than those obtained for shallow earthquakes (for direction $a, 59 \%$ and $28 \%$ of those for Models 1 and 2 respectively). In a recent study [35] of attenuation of peak ground accelerations in New Zealand, a term for $h_{C}$ was also found to be significant.

The effect of depth on MM intensity attenuation is illustrated by Figure 12, in terms of Models 2 and 3, for Crust, Slab $\left(S_{60}\right)$ and Deep earthquakes of $M_{W} 6.5$ and depths ranging from 10 to 150 $\mathrm{km}$. The tendency for deeper events to have higher intensities for the same magnitude and source distance, as predicted by the $h_{C}$ term, is clearly seen. For the same $M_{W}$ and source distance, the models predict that the intensities in direction $a$ are about 1.3 intensity units higher for events with $h_{C} 150 \mathrm{~km}$ than with $h_{C} 10$ $\mathrm{km}$, while the comparison between depths of 50 and $10 \mathrm{~km}$ gives an intensity increase of about 0.3 intensity units for events of the same focal mechanism.

\subsection{Effect of tectonic type}

Indicator variables for Crustal and Slab $\left(\mathrm{S}_{60}\right)$ tectonic types were included as candidate explanatory variables in Model 2 and Interface events in Model 1 (Crust, Slab and Interface are described in Figure 7). A positive crustal term appears in Model 2 , the parameter being largest for the $a$ direction. This helps the model reflect the small $b / a$ ratios of Crustal earthquakes of large magnitude.

It seems likely that the positive Crustal term in Model 2 is accounted for by the fact that the Crustal events database contains proportionately more Reverse $(22 \%)$ and Strike-slip $(42 \%)$ events than the Slab $\left(\mathrm{S}_{60}\right)$ database $(10 \%$ each), because of the higher intensities produced by events with those mechanisms as demonstrated by Model 1 (discussed later).

Regarding Interface earthquakes, a negative term appears in Model 1, predicting intensities about half an intensity unit smaller than other events of the same mechanism, $M_{W}, h_{C}$ and source distance. It is of interest that a study [35] of New Zealand peak ground accelerations found that the PGAs induced by the small subset of seven Interface events were weaker than those predicted for Crustal or Slab $\left(\mathrm{S}_{60}\right)$ events of the same $M_{W}$, $h_{C}$ and distance, which is consistent with the findings of the present study. Using a large international database, Youngs et al [42] also found that PGAs from Interface earthquakes were weaker than those of Crustal and Slab events, for the same magnitude and distance.

\subsection{Effect of focal mechanism}

Indicator variables for Normal, Strike-slip and Reverse focal mechanisms were included as candidate explanatory variables for Model 1, and combination products with magnitude and distance variables (e.g. $\delta_{\mathrm{R}} \cdot \mathrm{M}_{\mathrm{w}}$ and $\delta_{\mathrm{R}} \cdot \log D$ ) were also included. Such terms allow for shape differences between the attenuation functions for different focal mechanisms to be captured.

The differences indicated by Model 1 are illustrated in Figure 13. It is seen that for $h_{C}=10 \mathrm{~km}$ and the same magnitude and source distance, the model predicts generally that Reverse events give higher intensities than Strike-slip which in turn give higher intensities than Normal focal mechanism events, at most distances, and in both $a$ and $b$ directions, and always so near source. In addition the attenuation rate is higher for Reverse and Normal (i.e dipping fault) events than for Strike-slip earthquakes.

Both of the above results are similar to those of the 1991 Dowrick intensity study [6, 7], except that Normal and Strikeslip events were combined in that study because of the small data set. In their study of New Zealand PGA's, Zhao et al. [35] also found that Crustal Reverse events gave stronger shaking than Crustal + Slab $\left(\mathrm{S}_{60}\right)$ Strike-slip + Normal events (combined). Other studies of strong ground motion, by Spudich et al. [43] and Abrahamson \& Shedlock [44] suggest that crustal earthquakes with Normal focal mechanisms give smaller motions than Strike-slip. In addition Oglesby et al. [45] who carried out dynamic simulations of earthquakes on surface rupturing dipping faults, found that the ground motion from a Reverse fault is at least twice as strong as that from the equivalent Normal fault near the source. The difference between Reverse and Normal ground shaking predicted by our intensity model appears to be not quite so great. If the near source intensities from Model 1 for events of $M_{W} 7.0$ and $h_{C}=10 \mathrm{~km}$ are converted to PGAs, using a relation in which $\log _{10}$ PGA is proportional to $0.35 I$, the ratio of PGA for Reverse to Normal events is approximately 1.5 .

\subsection{Isoseismal shape}

Isoseismal shape varies with several factors, i.e. dip angle, focal mechanism, earthquake magnitude, depth, horizontal distance and $\mathrm{MM}$ intensity. Trends in isoseismal shape are best considered in terms of the ratio $b / a$ derived directly from the isoseismal distance data, as given in Table 2. Box plots shown in Figure 14 show the relationship of the shape parameter $b / a$ to other variables in the study. The white portion in the middle of each box plot indicates the median value, the solid black box shows the upper and lower quartiles while other horizontal lines and square bracket symbols indicate outliers. An outlier is any value more than 1.5 box-lengths beyond the end of the box. 


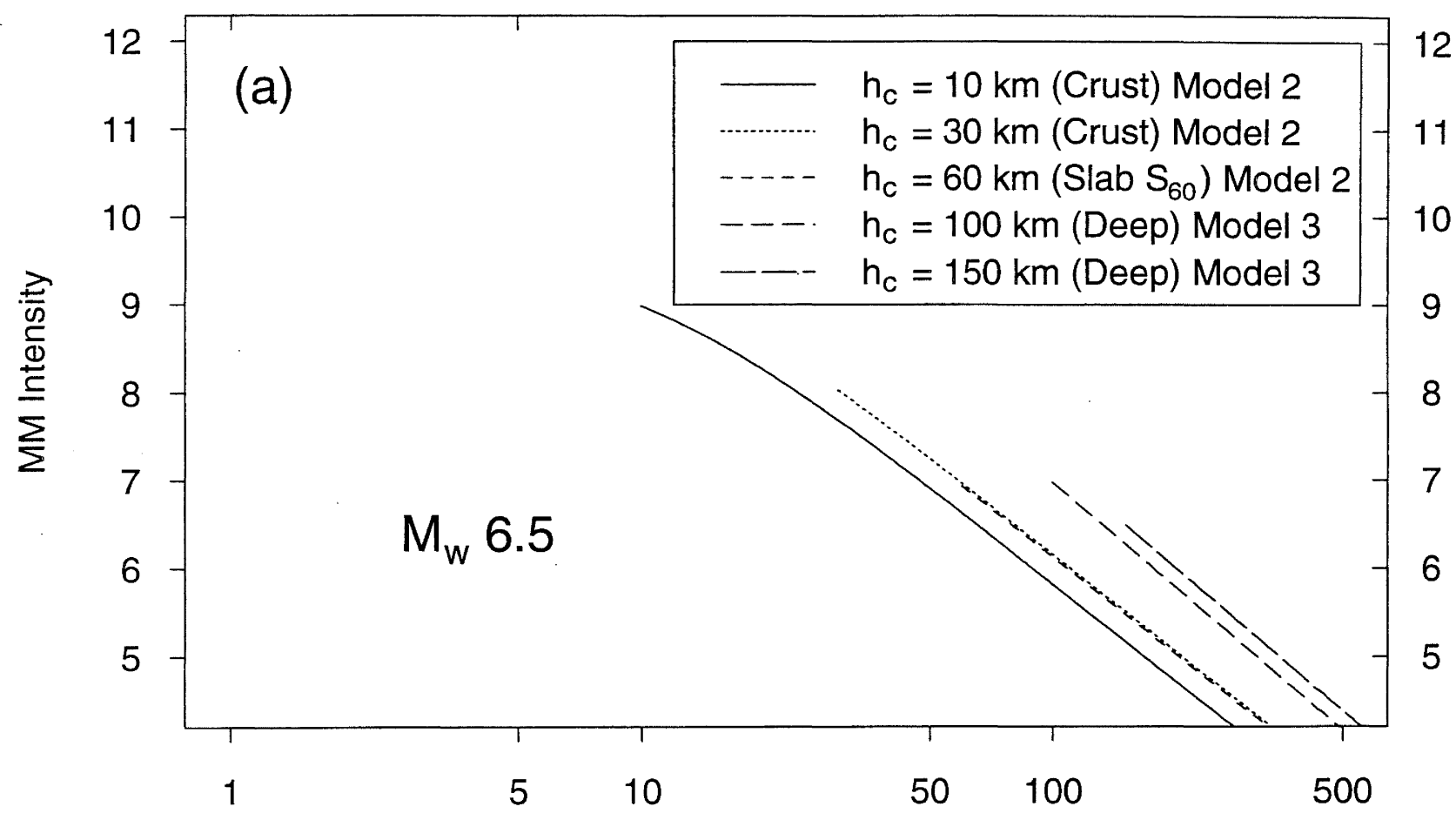

Source distance $r_{\mathrm{a}}(\mathrm{km})$

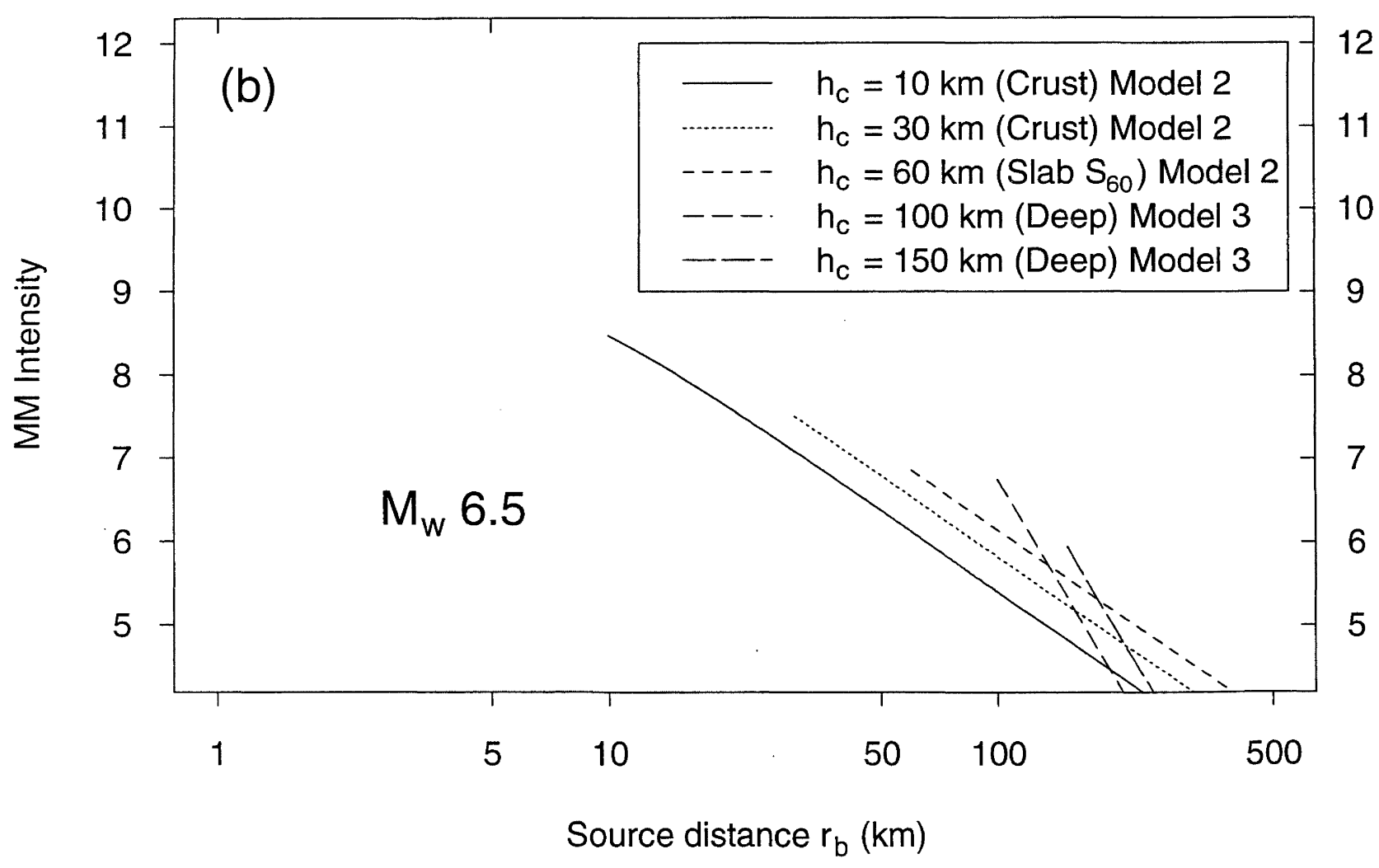

Figure 12: $\quad$ Effect of depth and Tectonic location. Intensity plotted against source distance $(a)$ in direction a, and (b) in direction $b$ as predicted by Models 2 and 3 for Crust, shallow Slab $\left(S_{60}\right)$ and Deep earthquakes of $M_{W} 6.5$ and depth $h_{C}=10,30$, 60,100 and $150 \mathrm{~km}$. Also note the high attenuation of Deep events in direction $b$. 

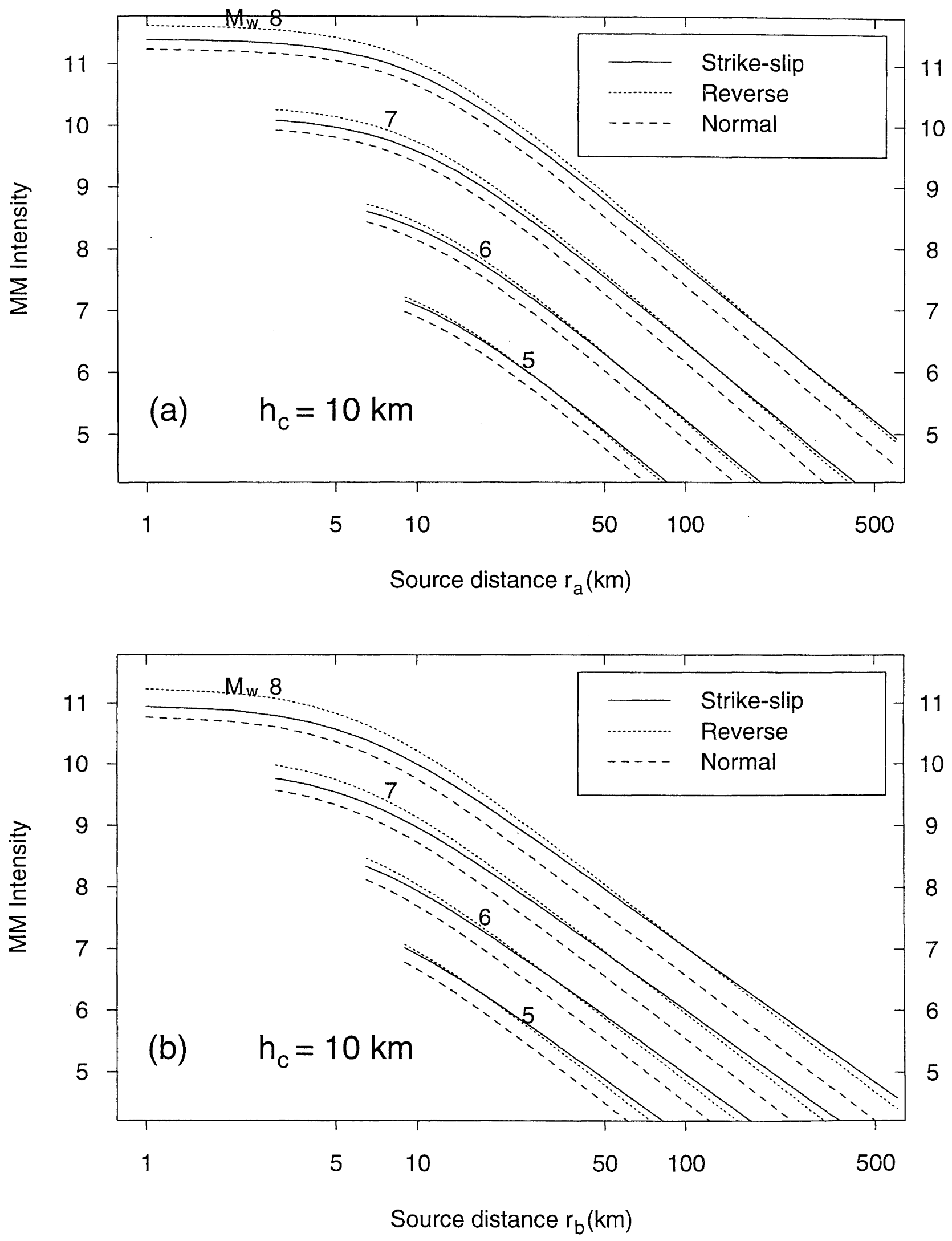

Figure 13: $\quad$ Effect of focal mechanism. Intensity plotted against source distance (a) along strike and (b) normal to strike, as predicted by Model 1 for Strike-slip, Reverse and Normal faulting earthquakes of $M_{W} 5,6,7$ and 8 and depth $h_{C}=$ $10 \mathrm{~km}$. 
All data

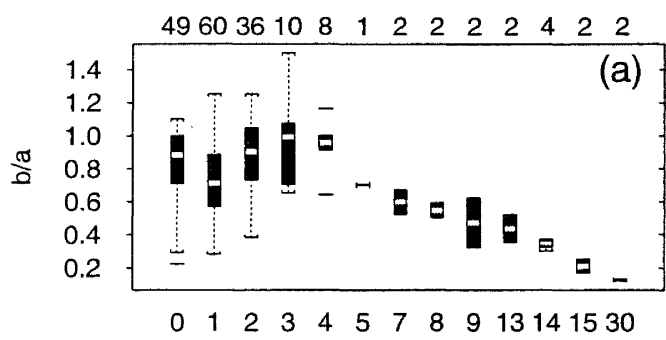

Centroid depth $(\mathrm{km} \times 10)$

All data except Deep region

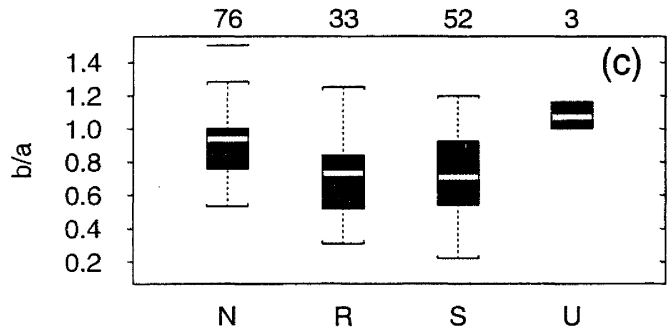

Focal mechanism

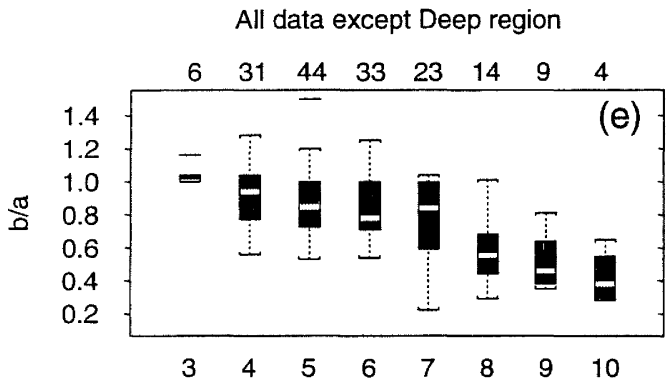

MM Intensity

All data

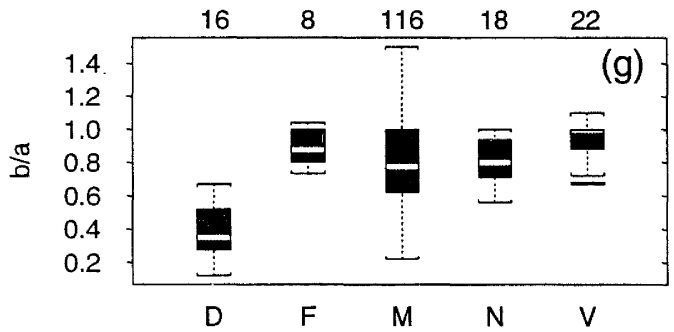

Region
$M_{w} \geq 6$ innermost isoseismal

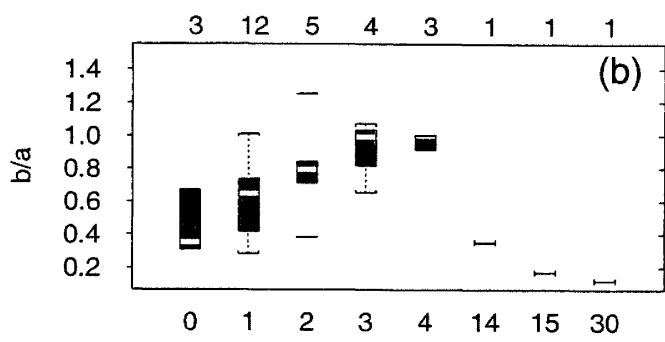

Centroid depth $(\mathrm{km} \times 10)$

$M_{w} \geq 6$ innermost isoseismal, except Deep region

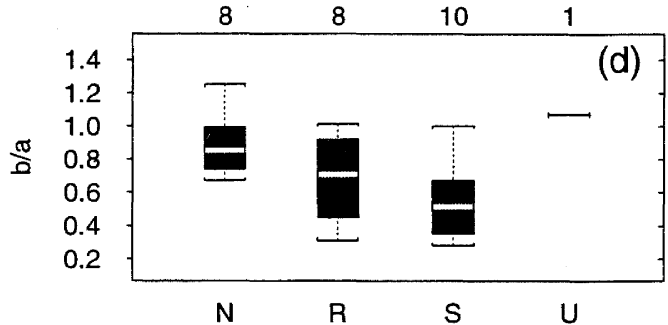

Focal mechanism

$M_{w} \geq 6$ innermost isoseismal, except Deep region

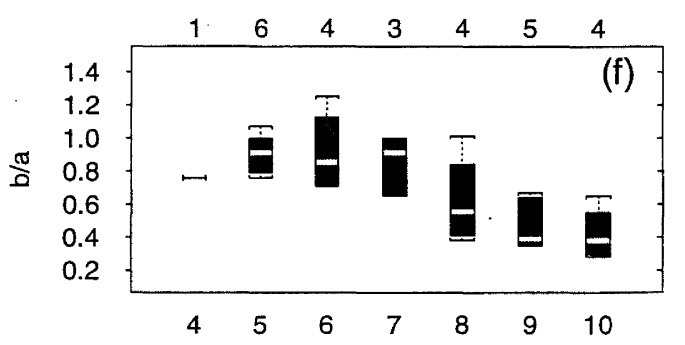

MM Intensity

Innermost isoseismal, except Deep region

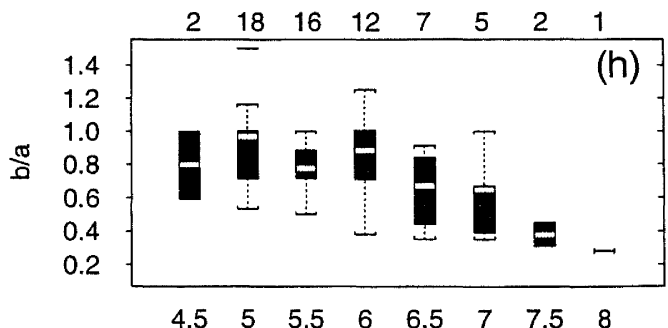

Moment magnitude

Figure 14: Shape of isoseismals in relation to strike illustrated by box plots of b/a data from Table 2. Variation of b/a is depicted in terms of $h_{C}$, focal mechanism, intensity, region and dip angle, comparing "all data" cases with these restricted to the inner isoseismals of events of $M_{W} \geq 6$. The numbers of data in the subsets are listed above each plot. At the foot of Figures $(a)$ and $(b)$ the numbers indicate $10 \mathrm{~km}$ depth increments, e.g. 0 indicates $0 \leq h_{C} \leq 9 \mathrm{~km}$. The white portion in the middle of each box plot indicates the median (see text). 
For earthquakes other than those classified as Deep, i.e. excluding events with $h_{C}>70 \mathrm{~km}$ in the subducting Pacific slab, a general observation regarding isoseismal shape is that they become more circular with increasing source distance, i.e. $b / a \rightarrow 1.0$. Also, the smaller the magnitude the more circular the isoseismals (Figure 14(h)), because small earthquakes approximate closely to being point sources. Thus, considering the innermost isoseismals of larger earthquakes $\left(M_{W} \geq 6\right)$ in Figure 14(b) it is seen that the median values of $b / a$ are 0.35 and 0.65 for $h_{C}<10 \mathrm{~km}$ and $10-19 \mathrm{~km}$ respectively, whereas for $h_{C}$ in the $30-50 \mathrm{~km}$ range the median $b / a$ is close to 1.0. Again in Figure 14(a), where all data are included, it is seen that the effect of the small earthquakes is to increase median $b / a$ to 0.9 for $h_{C}$ $<10 \mathrm{~km}$.

In a semi-empirical modelling study of the spatial distribution of PGAs from fault ruptures of large earthquakes, Midorikawa [46] found similar b/a patterns, with $b / a \sim 0.35$ near the fault of an earthquake of magnitude 7.2.

Figures 14(c) and (d) show how Strike-slip events tend to have more elongated isoseismals than do Normal and Reverse events, particularly for the inner isoseismals. This tendency is an effect of fault dip, $\beta$, Strike-slip earthquakes commonly having $\beta$ in the range $70-90^{\circ}$, while Normal and Reverse events have smaller $\beta$ (see Table 1). This trend was confirmed in dip angle terms (plots not shown).

When considering $b / a$ as a function of intensity, it is seen in Figures $14(\mathrm{e})$ and (f) that the median $b / a$ reduces almost linearly from about 1.0 at MM3 to 0.3 at MM10. In contrast to the above cases, median $b / a$ for the inner isoseismal and the "all data" cases is very similar for a given intensity.

Box plots of $b / a$ are shown in Figure $14(\mathrm{~g})$ for the four geographical regions of Figure 1 and the Deep earthquakes. The median $b / a$ values for Fiordland, North-west sub-region and the rest of the Main Seismic Region are similar at about 0.8 to 0.9, and are not statistically significantly different. The CVR has a slightly higher median $b / a$ of close to 1.0 , which is artificially high because its $b / a$ data are mostly for low intensities. Deep events have median $b / a \sim 0.35$ reflecting their consistently very elongated isoseismals, as discussed earlier.

The isoseismal shapes indicated by the $b / a$ data, are of course reflected in the attenuation models. This is illustrated in Figure 15 where the isoseismal maps as predicted by Model 1 are shown for four earthquakes of different source characteristics. In general the outer isoseismals have large $b / a$, and the smaller and deeper events, Figures 15(c) and (d), also have more circular isoseismals. It is noted that the near source spatial distribution of ground motions for large shallow events which is demonstrated by this study, and that of Midorikawa [46], is very different from that implied by the more simplistic modelling currently adopted in standard strong motion attenuation expressions, such as Refs. [35], [42-44]

\subsection{Regional effects}

In the past, a number of attempts have been made by various researchers $[2,3,6,35]$ to quantify possible regional differences in attenuation. In the present study, comparisons were made of data relating to the four geographical regions and Deep earthquakes shown in Figure 2. The events in these regions are identified in the Region columns of Table 1 as $\mathrm{F}$ (Fiordland), $\mathrm{N}$ (North-west), M (rest of the Main Seismic Region), V (CVR) and D (Deep). It was confirmed that there are strong regional attenuation effects differentiating the volcanic region, deep earthquakes, and earthquakes from the other regions. For that reason models were developed for the Central Volcanic Region and Deep earthquakes (Models 1 and 3). The bulk of the data are for what we call the Main Seismic Region and two models were developed for this region, Model 1 for the case where focal mechanisms are known, and Model 2 for the case where they are unknown or unspecified. No significant differences emerged between the Fiordland sub-region and the North-west sub-region and the rest of the Main Seismic Region. The above finding from our 10 Fiordland events is not consistent with that from a smaller data set (four events) for PGAs [35] which suggested that PGAs in Fiordland earthquakes are higher for a given set of parameter values than elsewhere in the country.

The differences that exist between the Main Seismic Region, the Central Volcanic Region and Deep earthquakes are indicated using Models 1 and 3 in Figure 16, in which has been plotted intensity against source distances $r_{a}$ and $r_{b}$ for events of $M_{W} 6.5$. These plots show the much higher attenuation of the CVR compared to the Main Seismic Region and the major axis direction $a$ of the Deep earthquakes. As CVR earthquakes generally have Normal focal mechanisms, a comparison is made using Model 1 of CVR events with Main Seismic Region Normal events in Figure 17. Two types of Normal mechanism event are modelled to have similar at-source intensities, and a large difference in attenuation rate.

The fit of the Deep earthquakes in direction $a$ was not perturbed by the inclusion of the very distant 1998 earthquake near Raoul Island (Event 85 ), which is in itself well fitted by Model 3. This is important for modelling the influence on hazard in the East Cape, of the belt of Subduction zone earthquakes stretching NNE of East Cape. Also apparent (Figure 16 (b)) is the very high effective attenuation of the Deep earthquakes in the minor axis direction $b\left(\mathrm{~N} 50^{\circ} \mathrm{W}\right)$, which models the phenomenon shown in the isoseismal map presented in Figure 5. For Deep earthquakes located in the dipping Pacific slab where it has lost contact with the Australian plate, i.e north-west of the line A-A on Figures 2 and 7, seismic waves travelling vertically or northwest have to traverse the highly attenuating mantle wedge to reach the ground surface. This effect occurs only on the northwest side of line A-A, attenuation on the south-east side apparently being normal, but insufficient distance data is available to quantify it because most of the area concerned is offshore.

Based on the difference found between attenuation inside and outside the CVR, our data being divided by the CVR boundaries (Figure 2), the geographical boundaries of the high attenuation volcanic region appear to lie close to those of the CVR, except that it is possible that the area north-west, west and south-west of Tauranga (i.e. NW of line B-B on Figure 2) may have normal (Main Seismic Region) attenuation characteristics. The latter proviso is made on the basis of the normal attenuation across that zone exhibited by the $1972 \mathrm{Te}$ Aroha earthquake (Figure 11), and the high attenuation exhibited by the 1976 October 27 Te Puke earthquake in the zone just east of Tauranga. 
(a) $M_{w} 7.5, h_{c} 8, h_{t}=0$, Strike slip

(b) $M_{w} 7.5, h_{c} 8, h_{t}=0$, Reverse
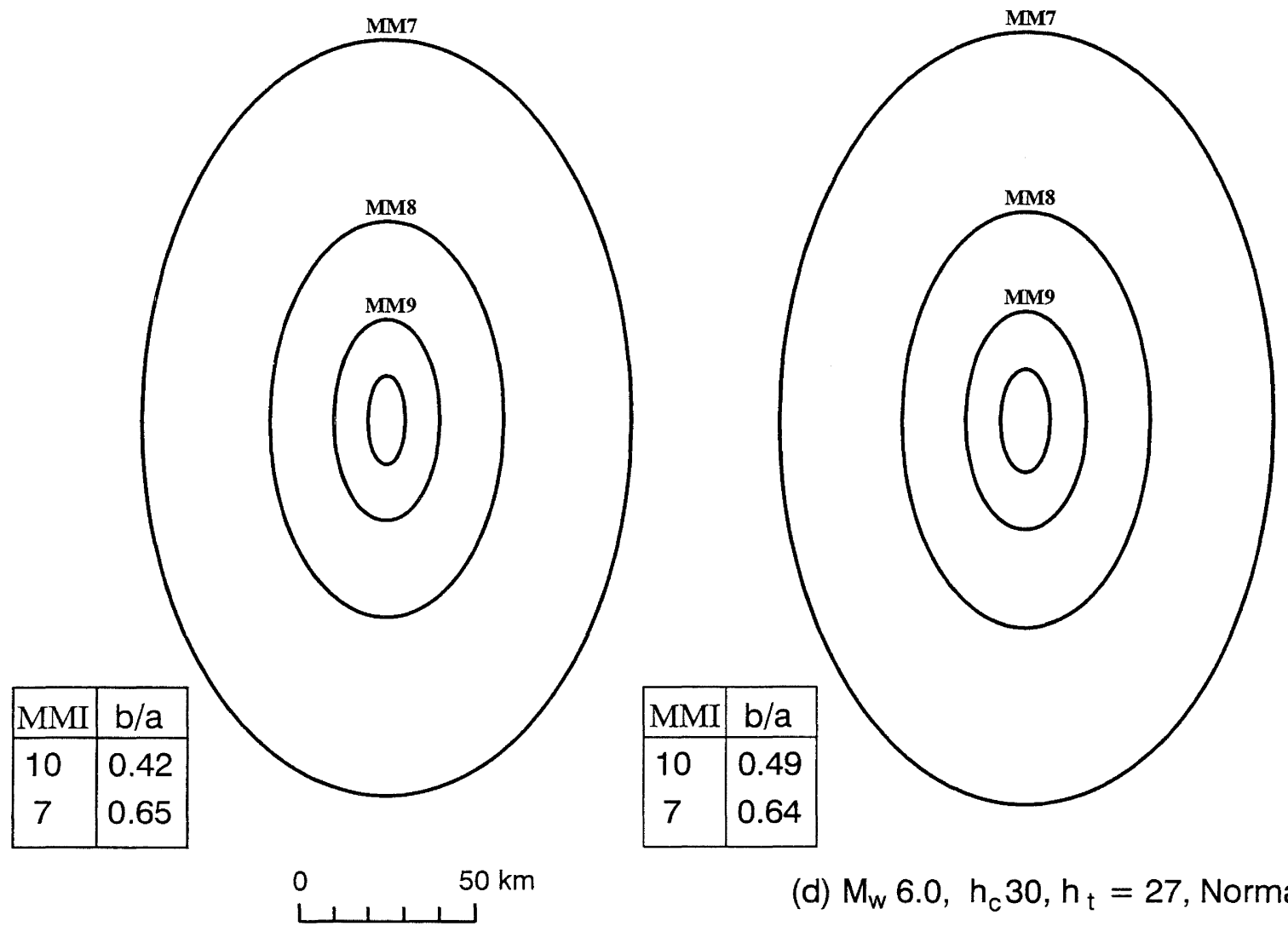

(d) $M_{w} 6.0, h_{c} 30, h_{t}=27$, Normal

(c) $M_{w} 6.0, h_{c} 5, h_{t}=1.5$, Normal
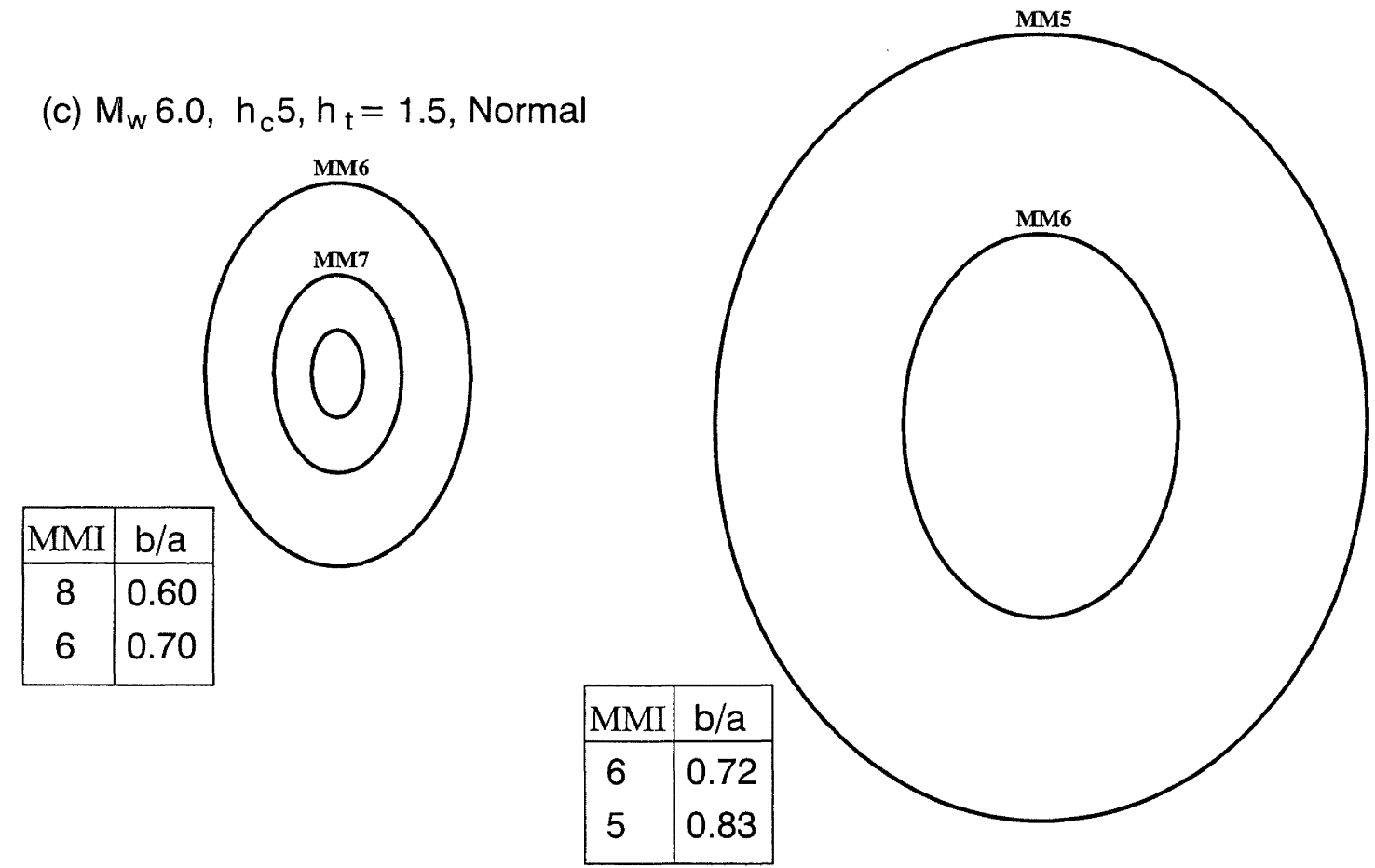

Figure 15: Illustration of isoseismal dimensions and shapes predicted by attenuation Model 1, for earthquakes of various source parameters. The ratio b/a is seen to increase with (i) source distance, (ii) depth, and (iii) decreasing magnitude. 

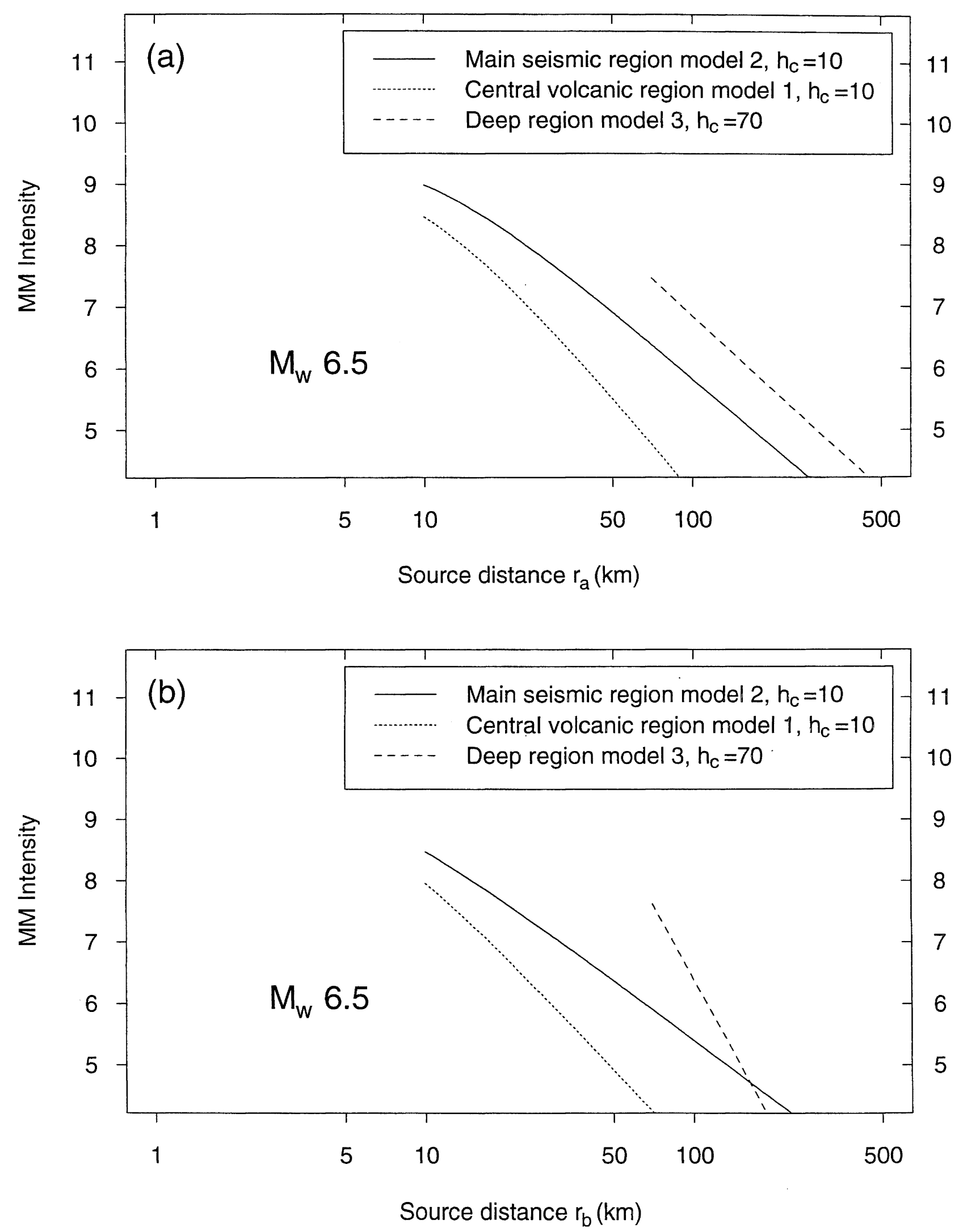

Figure 16: Effect of region. Intensity plotted against source distance (a) along strike and (b) normal to strike, as predicted by Models 2, 1 and 3 for earthquakes of $M_{W} 6.5$ in the Main Seismic Region $\left(h_{C}=10 \mathrm{~km}\right) \mathrm{CVR}\left(h_{C}=10 \mathrm{~km}\right)$ and Deep events $\left(h_{C}=70 \mathrm{~km}\right)$, respectively. 


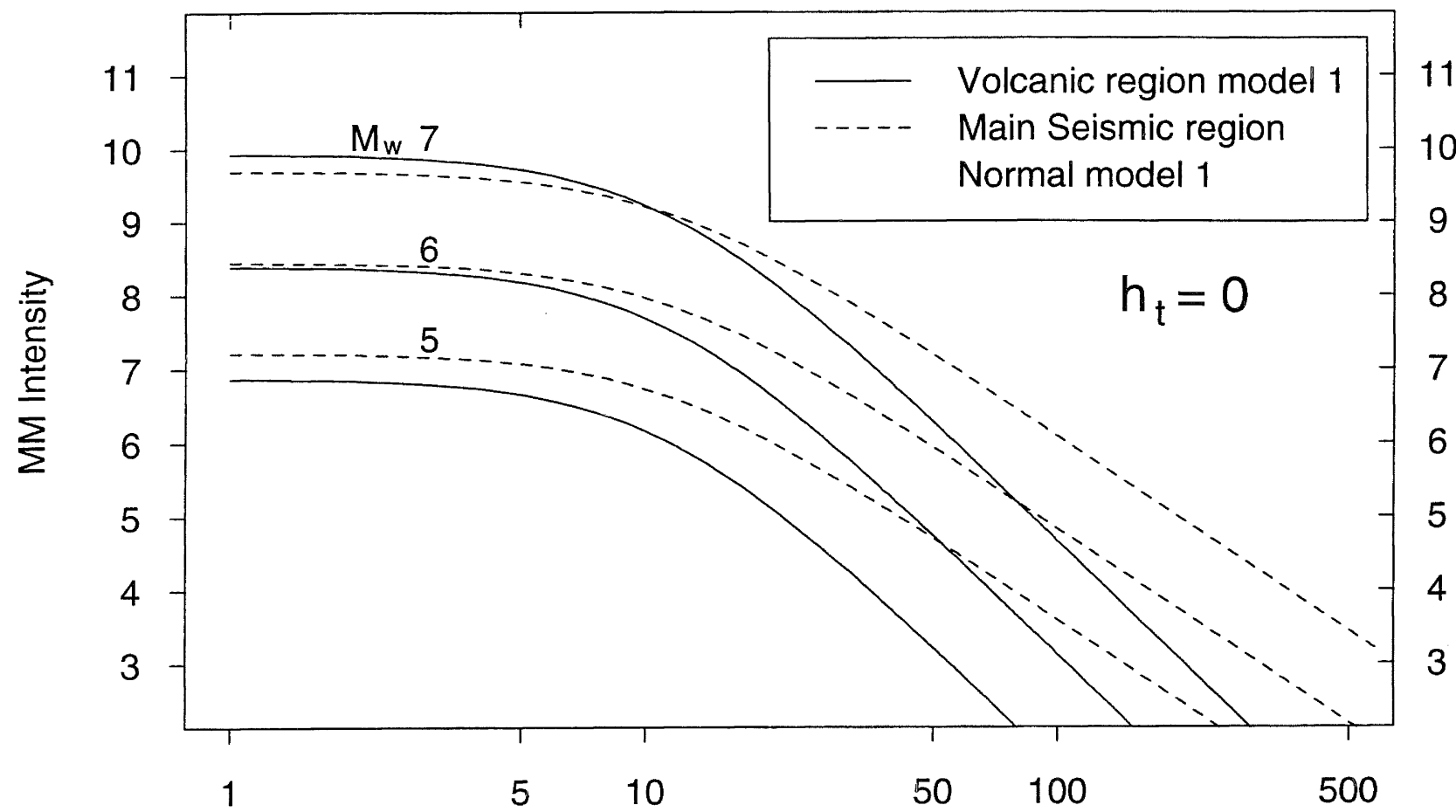

Horizontal distance a $(\mathrm{km})$

Figure 17: Comparison of Central Volcanic Region attenuation model with that for surface rupturing Main Seismic Region Normal faulting events.

\subsection{COMPARISONS WITH OTHER NEW ZEALAND ATTENUATION MODELS}

Because of their widespread use in recent years, it is also of interest to compare the models published in 1991 and 1992 by Dowrick $[6,7]$ with those of the present study. A direct comparison can be made in terms of focal mechanism, mean isoseismal radius $c$, and the centroid depth $h_{C}$ (which equates to the effective depth $h_{e}$ used earlier $\left.[6,7]\right)$. Such a comparison is made in Figure 18 for earthquakes of $M_{W} 5.0$ to 8.0 , all with $h_{C}=$ $10 \mathrm{~km}$. In comparing the models for Reverse focal mechanism earthquakes, it is seen that the 1991 and the present models are virtually identical near the source throughout the magnitude range, while at distances greater than about $5 \mathrm{~km}$ the 1991 model predicts greater intensities (by up to 0.5 intensity units) than the present model, for $M_{W} \geq 6$. It thus may be inferred from Figures 18(a) and 10, that the 1991 Dowrick model gives estimates of the size of the inner isoseismals of the two large shallow of 1929 and 1931 (Nos. 14 and 15) which are within the range of normal scatter of the better defined isoseismals now available. This is comforting in the light of some earlier concerns $[3,8]$.

Because the other focal mechanism model of Dowrick (1991) combined Normal and Strike-slip events, it is not fully comparable with the present Strike-slip model. The fact that the two models are closest at high magnitudes (Figure 18 (b)) may be due to the fact that the weaker Normal events are represented in the 1991 dataset only in the smaller magnitudes i.e. $M_{s}(\max )$ $\leq 6.6$.

The attenuation models of Smith [3] were found to differ substantially from those of this study (by up to \pm 1.0 intensity units), the differences apparently arising mainly from the different data used in the two studies, as noted in general terms in Section 1.0 above. Smith did not define depths explicitly, but for shallow earthquakes in the Main Seismic Region classified earthquakes as either (1) Upper Crust or (2) Lower Crust. Of 54 events in these two classes, the classifications for 21 earthquakes appear to be at variance with present information on centroid depths and aftershock patterns, e.g. the 1979 Oct. 12 event of $h_{C}$ $12 \mathrm{~km} \mathrm{[21]} \mathrm{and} \mathrm{the} 1990$ May 13 event of $h_{C} 13 \mathrm{~km} \mathrm{[22,29]}$ were both classed as Lower Crust. In addition the magnitudes used by Smith differed from those used in the present study, which are restricted to moment magnitudes. Of the 107 earthquakes in Smith's data set, the magnitudes of 68 were local magnitudes $\left(M_{L}\right)$ which have been shown [34] to be poor indicators of moment magnitude. This is illustrated by the fact that the $M_{L}$ values in Smith's data set differ from $M_{W}$ on average by 0.3 and the differences range from +0.8 to -0.7 . 

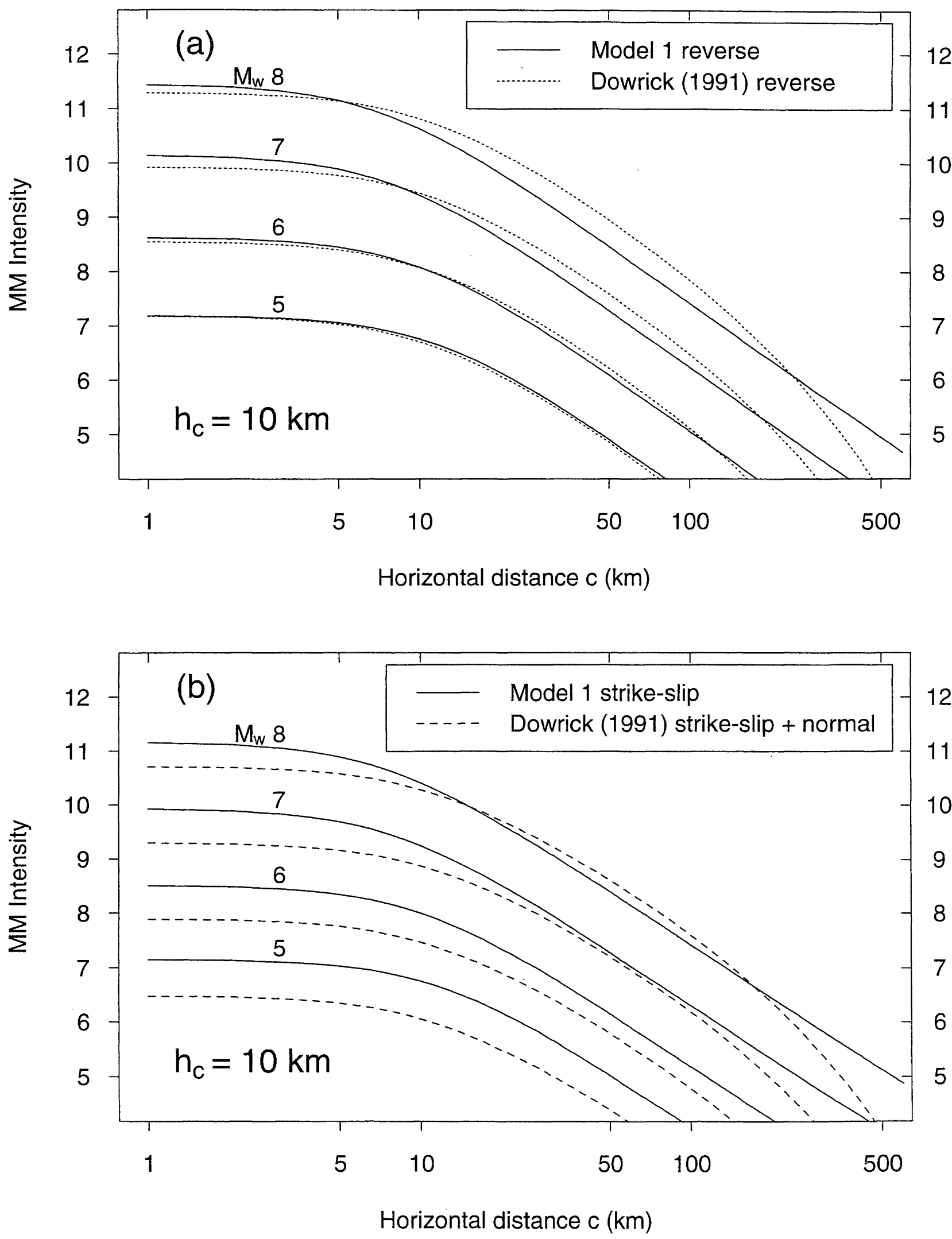

Figure 18: Comparison of attenuation models of Dowrick (1991) with Model 1, for (a) Reverse faulting events, and (b) Strike-slip + Normal versus Strike-slip (Model 1), in terms of mean horizontal distance c, and $h_{C}=10 \mathrm{~km}$. 


\section{ESTIMATING SOURCE DISTANCE}

The regression analyses carried out in this study were designed for the estimation of the isoseismal intensity as a function of $M_{W}$, distance $D$, and depth $h_{C}$, as in Equation (5). Sometimes, however, it may be desired to estimate other parameters when $I$ is given, e.g. the source distances may be required for drawing scenario maps. A convenient way of doing that is simply to invert Equation (5) to find distance, using the appropriate parameter values given in Tables 1-3.

Thus the horizontal distances $a, b, c$ of Figure 3 may be estimated from an expression of the form

$a=\left[10^{2\left(I-A_{1}-A_{2} M_{W}-A_{4} h_{C}\right) / A_{3}}-d^{2}-h_{t}^{2}\right]^{1 / 2}$

The above procedure involves an added approximation because strictly speaking the parameters $A_{1}-A_{4}$ should be estimated from regressions of $\log D$ on $I$ rather than $I$ on $\log D$ as was done for obtaining the estimates in Tables 3-5.

However comparisons of the results obtained carrying out the two regressions, show that the estimates of $I$ or distance are almost identical. This suggests that inversions of Equation (5) may be used to estimate any of the variables without significant extra error

\subsection{VARIABILITY OF LOCAL OBSERVATIONS OF INTENSITY}

In New Zealand, standard seismological practice is to draw isoseimals as lines enclosing most of the local observations of intensity of the isoseismal concerned. Thus considering the isoseismal map of the 1979 Puysegur Bank earthquake (Figure 6) it is seen that the MM5 isoseismal encloses all but one MM5 observation, and the MM4 isoseismal contains all of the MM4 observations. As the variability of the local observations is sometimes of interest it was decided to examine the statistical distributions of local observations of intensity from a sample of the events considered in this study. The 17 events chosen were rich in data, having a total of 1130 intensity observations, and ranged in magnitude from 5.3 to 7.8 . The number of observations of each level of intensity within each intensity zone were counted. Intensity zones are defined as the areas between adjacent isoseismals, e.g. the MM4 zone lies between the MM4 and MM5 isoseismals (and hence contains mostly MM4 local observations as seen typically in Figure 6).

For each intensity zone estimates were made of

- the mean deviation from the nominated intensity for the zone.

- the standard deviation of the observations from the mean and RMS deviation from the nominated intensity for the zone.

The results of the above calculations are given in Table 6 and an example plot of the deviations from the mean are given for MM8 in Figure 19. First it is seen that the mean of the local intensities is generally slightly lower than the zone intensity (about 0.2 units lower on average). This is a natural consequence of the way the isoseismals are located in New Zealand practice. In Table 6 it is also seen that the standard deviation of the local observations is 0.64 in relation to the full data set, with no significant trend with intensity. This additional local variability needs to be taken into account if the attenuation relations presented here are used to estimate intensities at particular locations, and not just mean isoseismal intensities, in scenario events.

The statistics in Table 6 incorporate the effects of all ground conditions from the reporting areas, which are alluvial much more frequently than rock in New Zealand. While the data does not allow us to differentiate between different ground classes, it is of interest to note a finding from a study [47] of seismic hazard of the city of Christchurch which has large areas of alluvium of varying degrees of responsiveness. In the 22 intensity maps having isoseismals of MM4 or stronger affecting Christchurch, the local intensities reported from Christchurch alluvial areas (which are mostly firm-stiff) were on average (only) 0.1 of an intensity unit higher than the isoseismal value of the corresponding intensity zone. This supports the contention that New Zealand intensity attenuation models relate to firm to stiff soil sites.

\subsection{CONCLUSIONS}

As a result of this study, the following conclusions were drawn:

1. Attenuation expressions have been derived for Modified Mercalli intensity isoseismals in New Zealand earthquakes in terms of magnitude $M_{W}$ and source distance. The expressions allow for the influence of depth, focal mechanism, tectonic type and region, and attenuation along and normal to the strike of the source rupture (a new procedure)

2. All of the models were found to be reasonably robust in statistical terms, and plots of models against the data for each event showed the fit to be good in most cases. The shape of the attenuation curves over long distances is well supported by those events having three or more data. However the models are not recommended for application outside of the range of the data.

3. Distance is accounted for as the logarithm of a function of the distance from the top of the fault rupture to the isoseismal. Three distance measures were modelled, i.e. radius along strike, radius normal to strike and the mean radius.

4. There is no sign either of magnitude saturation effects or that the attenuation rate varies with magnitude despite having data with a large magnitude range, $4.9 \leq M_{W} \leq$ 8.2 .

5. Depth is accounted for explicitly as a function of centroid depth. For events with depths down to about 60 $\mathrm{km}$ the depth effect is moderate, eg events with depths of $60 \mathrm{~km}$ cause predicted mean intensities approximately 0.5 units higher than those of events with depths of 10 $\mathrm{km}$, when magnitude, source distance and focal mechanism are held equal. 
Table 6: Deviation of local observations of intensity from the "nominated" intensity of the zone

\begin{tabular}{|lcccc|}
\hline $\begin{array}{l}\text { MMI } \\
\text { Zone }\end{array}$ & Mean dev. & Std dev. & RMS dev. & $\mathrm{n}$ \\
\hline 4 & & & & \\
\hline 5 & -0.07 & 0.55 & 0.56 & 295 \\
6 & -0.18 & 0.66 & 0.68 & 361 \\
7 & -0.19 & 0.67 & 0.70 & 174 \\
8 & -0.24 & 0.83 & 0.86 & 164 \\
9 & -0.16 & 0.51 & 0.54 & 111 \\
All & -0.24 & 0.52 & 0.57 & 25 \\
& -0.18 & 0.64 & 0.66 & 1130 \\
\hline
\end{tabular}

MMI deviation

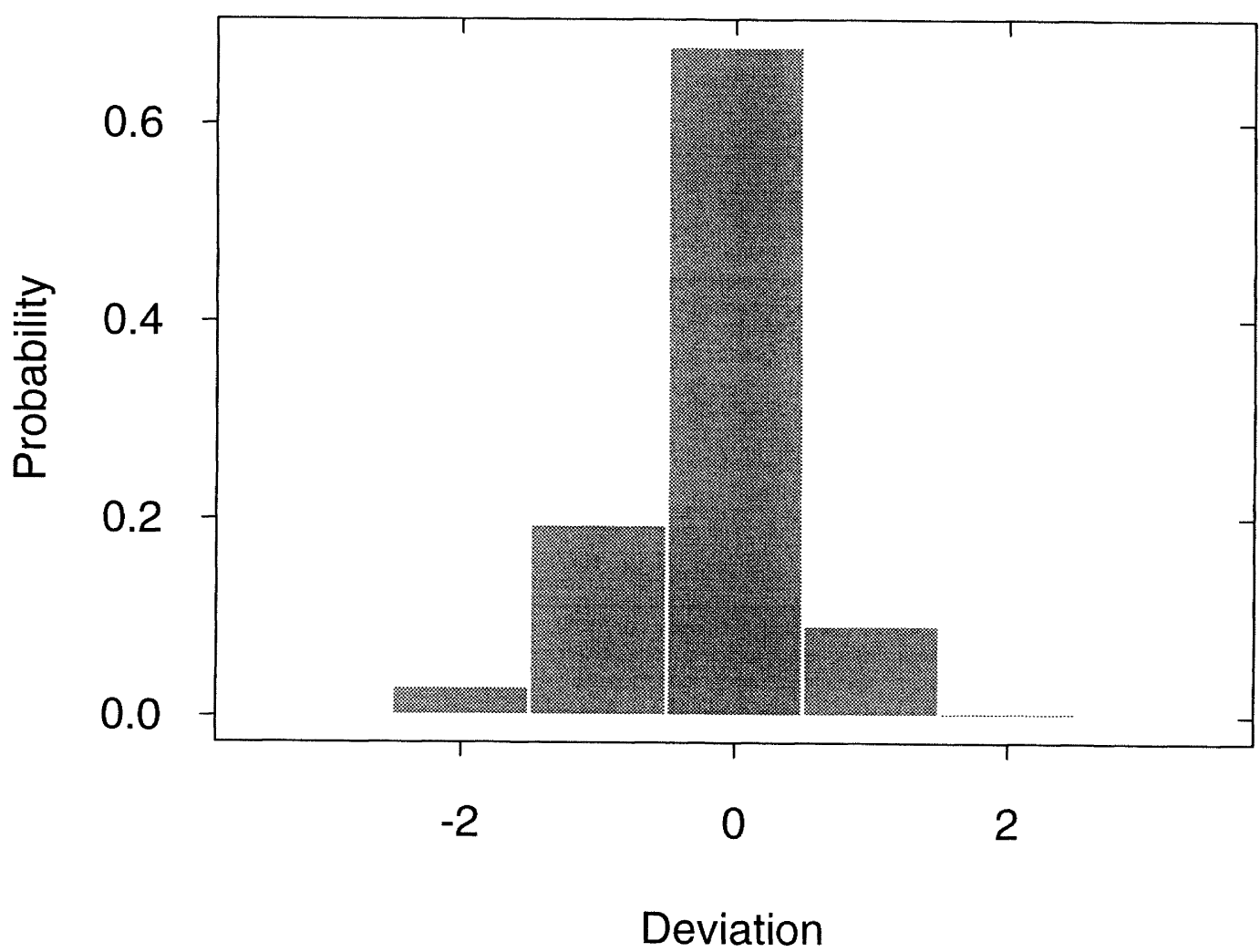

Figure 19: Probability of deviations of local intensity from the nominated intensity of their zone. 
6. Shallow earthquakes ( $h_{C} \leq 60 \mathrm{~km}$ and excluding CVR and Interface events) with different focal mechanisms were found to have different attenuation characteristics. Reverse events were found to cause predicted mean intensities that were mostly higher than those of Strikeslip events, which in turn were higher than those of Normal events, for the same magnitude, depth and distance. Reverse and Normal events were found to have higher attenuation rates than Strike-slip events.

7. The intensities of the four Interface earthquakes in the data set are lower on average by about 0.5 intensity units than those predicted by Model 1 for events of the same magnitude, depth and focal mechanism. This is consistent with the predictions for PGAs from a models based on New Zealand data [35] and on world-wide data [43].

8. The rate of attenuation of intensity was found to be substantially higher within the Central Volcanic Region than in other parts of the country.

9. The geographical boundaries of the high attenuation volcanic region appear to lie close to those of the CVR, except that (on the evidence of one earthquake) the area north-west, west and south-west of Tauranga may have normal attenuation characteristics.

10. Attenuation related to both the Fiordland and the Northwest sub-regions was found to be consistent with that of the rest of the Main Seismic Region.

11. Deep earthquakes $\left(h_{C} \geq 70 \mathrm{~km}\right)$ in the subducting Pacific slab have a very high attenuation rate in the $\mathrm{N} 50^{\circ} \mathrm{W}$ direction, while in the major axis direction $\mathrm{N} 40^{\circ} \mathrm{E}$ the attenuation rate is about the same as for shallow Main Seismic Region events (Model 1). Their attenuation rate in the south-east direction is apparently not highly attenuated as it is in the opposite direction, but has not been modelled due to lack of data.

12. Isoseismal shape, measured by the ratio $b / a$ (radius normal to strike over radius along strike) has strong dependencies on magnitude, source distance, intensity and fault dip. The ratio $b / a$ is about 0.4 near the source of large magnitude shallow strike-slip earthquakes with near vertical fault rupture; $b / a$ tends to 1.0 with decreasing magnitude and increasing source distance, except for Deep events in the subducting Pacific plate.

13. The near source spatial distribution of ground motions for large shallow earthquakes differs substantially from that predicted by standard strong motion attenuation models.

14. The mean value of local observations of intensity between adjacent isoseismals (i.e. within an intensity zone) was found to be about 0.2 intensity units lower than the nominated intensity for the intensity zone. The standard deviation of the local observations was found to be 0.64 across the full range of intensity zones considered (MM4 to MM9).
15. The expressions presented here for estimating intensity may be inverted for estimating distances to isoseismals of given intensities, without significant added error arising from using MMI as the dependent variable in the regression.

16. The 1991 attenuation model of Dowrick $[6,7]$ is quite similar to that of this study for shallow $\left(h_{C}=10 \mathrm{~km}\right)$ Reverse faulting earthquakes. The 1991 lumping together of Strike-slip and Normal earthquakes, resulted in under- and over-estimations of the intensities of these two mechanisms respectively when compared to the present model for shallow Strike-slip $\left(h_{C}=10 \mathrm{~km}\right)$ earthquakes.

\section{ACKNOWLEDGEMENTS}

The authors are grateful for constructive in-house reviews of the manuscript by our colleagues G. McVerry, W. Smith and J. Zhao, and also to the many others who prepared intensity maps over many decades. The thoughtful comments of an unknown reviewer are gratefully acknowledged. This study was funded by FRST over a number of years, the most recent being under Contract No. C05506.

\section{REFERENCES}

1. Walley, P. (1976), The estimation of earthquake risk in New Zealand, Technical Report No. 49, Department of Scientific and Industrial Research, Applied Mathematics Division.

2. Smith, W.D. (1978), Spatial distribution of felt intensities for New Zealand earthquakes, NZ Jnl of Geology and Geophysics, 21, 293-311.

3. Smith, W.D. (1995), A development in modelling of farfield intensities for New Zealand earthquakes, Bulletin NZ National Society for Earthquake Engineering, 28(3), 196-217.

4. Smith, W.D. (1995), A procedure for modelling nearfield earthquake intensities, Bulletin NZ National Society for Earthquake Engineering, 28(3), 218-223.

5. Matuschka, T. (1980), Assessment of seismic hazard in New Zealand, Report No. 222, Department of Civil Engineering, University of Auckland.

6. Dowrick, D.J. (1991), A revision of attenuation relationships for Modified Mercalli intensity in New Zealand earthquakes, Bulletin NZ National Society for Earthquake Engineering, 24(3), 210-224.

7. Dowrick, D.J., (1992), Attenuation of Modified Mercalli intensity in New Zealand earthquakes, Earthquake Engineering \& Structural Dynamics, 21, 181-196.

8. Andrews, A.L., and Butcher, G.W. (1992), Intensity of shaking generated by large shallow New Zealand 
earthquakes, Bulletin NZ National Society for Earthquake Engineering, 25(4), 358-360.

9. Grapes, R. and Downes, G. (1997), The 1855 Wairarapa, New Zealand, earthquake - Analysis of historical data, Bulletin NZ National Society for Earthquake Engineering, 30(4), 271-368.

10. Cowan, H.A. (1991), The North Canterbury earthquake of September 1, 1888, Journal Royal Society of New Zealand, 21(1), 1-12.

11. Reyners, M.E., Institute of Geological \& Nuclear Sciences (in preparation). Map published in Ref. 10.

12. Downes, G.L. (1995), Atlas of isoseismal maps of New Zealand, Monograph 11, Institute of Geological \& Nuclear Sciences, Lower Hutt, New Zealand.

13. Dowrick, D.J. (1994), Damage and intensities in the magnitude 7.8 1929 Murchison, New Zealand, earthquake, Bulletin NZ National Soc. for Earthq. Eng., 27(3), 190-203.

14. Dowrick, D.J. (1998), Damage and intensities in the magnitude 7.81931 Hawke's Bay, New Zealand, earthquake, Bulletin NZ National Soc. for Earthq. Eng., 31(3), 139-163.

15. Downes, G.L., Dowrick, D.J., Smith, E.G.C. and Berryman, K.R., The 1934 Pahiatua earthquake sequence: Analysis of observational and instrumental data. (in preparation).

16. Dowrick, D.J., New MM Intensity isoseismals for 12 earthquakes 1922-1942, previously available only in as Rossi-Forel conversions to MMI in Ref 12. (Work in progress).

17. Dowrick, D.J., Isoseismal maps for 12 earthquakes 1901-1985, not previously mapped. Also maps for Events 91, 82, 84, 85. (Work in progress).

18. Dowrick, D.J., Complete revisions of 15 isoseismal maps in Ref. 12, from period 1948-1990, and a revision of map for Event 83. (Work in progress).

19. Darby, D.J. and Beanland, S. (1992), Possible source models for the 1855 Wairarapa earthquake, New Zealand, Journal of Geophysical Research, 89, 1237512389.

20. Sykes, L., Lamont-Doherty Earth Observatory of Columbia University, Unpublished study of 1855 Wairarapa earthquake.

21. Anderson, H., Webb, T. and Jackson, J. (1993), Focal mechanisms of large earthquakes in the South Island of New Zealand: implications for the accommodation of Pacific-Australia plate motion, Geophysical Journal International, 115, 1032-1054.
22. Webb, T.H. and Anderson, H. (1998), Focal mechanisms of large earthquakes in the North Island of New Zealand: slip partioning at an oblique active margin, Geophysical Journal International, 134, 40-86.

23. Webb, T.H., (Institute of Geological \& Nuclear Sciences, pers. comm), Unpublished focal mechanism study of Fiordland earthquake of 1993 August 10.

24. Reyners, M., McGinty, P. and Gledhill, K. (1998), The Ormond, New Zealand, earthquake of 1993 August 10: rupture in the mantle of the subducted Pacific plate, New Zealand Journal of Geology and Geophysics, 41, 179185.

25. Dziewonski, A.M. et al. Centroid movement tensor solutions........ Physics of the Earth and Planetary Interiors, various issues.

26. Doser, D.I. and Webb, T.H., Source parameters of large historic (1918-1961) earthquakes, South Island, New Zealand, (submitted to Geophysical Journal International).

27. Doser, D.I. and Webb, T.H. (in preparation), Source parameters of large historic (1917-1961) earthquakes, North Island, New Zealand.

28. McGinty, P., Robinson, R., Taber, J. and Reyners, M. (1997), The 1990 Lake Tennyson earthquake sequence, Marlborough, New Zealand, New Zealand Journal of Geology and Geophysics, 40, 521-535.

29. Robinson, R. (1994), Shallow subduction tectonics and fault interaction: The Weber, New Zealand, earthquake sequence of 1990-1992, Journal of Geophysical Research, 99, B5, 9663-9679.

30. Reyners, M., McGinty, P., Ansell, J. and Ferris, B. (1997), Movement at the plate interface in Southern Hawke's Bay; the Tikokino earthquake of 11 April 1993 , Bulletin NZ National Soc. for Earthq. Eng., 30(3), 242251.

31. Reyners, M., Gledhill, K., Waters, D. (1991), Tearing of the subducted Australian plate during the Te Anau, New Zealand, earthquake of 1998 June 3, Geophysical Journal International, 104, 105-115.

32. Ansell, J. and Bannister, S. (1996), Shallow morphology of the subducted Pacific plate along the Hikurangi margin, New Zealand, Physics of the Earth and Planetary Interiors, 93, 3-20.

33. Anderson, H. and Webb, T. (1994), New Zealand seismicity: patterns revealed by the upgraded national seismograph network, New Zealand Joumal of Geology and Geophysics, 37, 477-493.

34. Dowrick, D.J. and Rhoades, D.A. (1998), Magnitudes of New Zealand earthquakes, Bulletin NZ National Soc. For Earthquake Eng., 31(4), 260-280. 
35. Zhao, J.X., Dowrick, D.J. and McVerry, G.H. (1997), Attenuation of peak ground accelerations in New Zealand earthquakes, Bulletin NZ National Soc. for Earthq. Eng., 30(2), 133-158.

36. Hancox, G.T., Perrin, N.D. and Dellow, G.D. (1997), Earthquake-induced landsliding in New Zealand and implications for MM intensity and seismic hazard assessment, Client Report $43601 B$, prepared for the Earthquake Commission by Institute of Geological and Nuclear Sciences, Lower Hutt.

37. Akaike, H. (1974), A new look at the statistical model identification, IEEE Trans. Auto. Control, AC-19 (6), 716-723.

38. Abrahamson, N.A. and Youngs, R.R. (1992), A stable algorithm for regression analysis using the random effects model. Bulletin of the Seismological Society of America, 82, 505-510.

39. Rhoades, D.A. (1997), Estimation of attenuation relations for strong-motion data allowing for individual earthquake magnitude uncertainties. Bulletin of the Seismological Society of America, 87, 1674-1678.

40. Uhrhammer, R.A., Loper, S.J. and Romanowicz, B. (1996), Determinations of local magnitude using BDSN Broadband Records. Bulletin of the Seismological Society of America, 86, 1314-1330.
41. Wells, D.L. and Coppersmith, K.J. (1994), New empirical relationships among magnitude, rupture length, rupture width, rupture area, and surface displacement. Bulletin of the Seismological Society of America, 84, 974-1002.

42. Youngs, R.R., Chiou, S. -J., Silva, W.J. and Humphrey, J.R. (1997), Strong ground motion attenuation relations for subduction zone earthquakes, Seismological Research Letters, 68(1), 58-73.

43. Spudich, P. and 10 others (1997), SEA96 - A new predictive relation for earthquake ground motions in extensional tectonic regimes, Seismological Research Letters, 68(1), 190-198.

44. Abrahamson, N.A. and Shedlock, K.M. (1997), Overview, Seismological Research Letters, 68(1), 9-23.

45. Oglesby, D.D., Archuleta, R.J. and Nielsen, S.B. (1998), Earthquakes on dipping faults: The effects of broken symmetry, Science, 280, 15 May, 1055-1059.

46. Midorikawa, S. (1993), Semi-empirical estimation of peak ground acceleration from large earthquakes, Tectonophysics, 218, 287-295.

47. Dowrick, D.J., Berryman, K.R., McVerry, G.H. and Zhao, J.X. (1998), Earthquake hazard in Christchurch, Bulletin NZ National Soc. for Earthq. Eng., 31(1), 1-23. 